Artículo de Reflexión

Apuntes del CENES

ISSN 0120-3053

Volumen $34-\mathrm{N}^{\circ} .60$

julio - diciembre 2015

Págs. 41-94

\title{
Conexiones alienadas entre economía, marketing y globalización
}

\author{
Alienated connections between economy, \\ marketing and globalization
}

Conexões alienaram entre economia, marketing e globalização

Jorge Enrique Garcés Cano*

Fecha de recepción: 16 de octubre de 2014

Concepto de evaluación: 3 de febrero de 2015

Fecha de aprobación: 25 de junio de 2015

* Economista, Universidad Nacional de Colombia. PhD (C) en Ciencias Económicas. MsC en Psicología del Consumidor. Especialista en Teoría y Política Económica, U. Nacional de Colombia. Asesor, Consultor e Investigador Independiente. Catedrático de la Universidad del Norte. Barranquilla, Colombia. Dirección postal: Cra 92bis \# 82ª 39. Bogotá, Colombia. Correo electrónico: jegarcacimarron@yahoo.com 


\section{Resumen}

Este artículo constituye un esfuerzo teórico-conceptual y descriptivo por entender las conexiones entre una teoría del marketing con real foco en el consumidor (el papel de la demanda) y los aspectos socioculturales, ideológicos, políticos y económicos de los autores del macromarketing, que se asumen divergentes de un micromarketing cuyo origen neoclásico ha impedido su conceptualización desde la ciencia y su método; máxime en esta etapa del capitalismo, en que los efectos de la globalización se manifiestan sobre los habitantes del planeta Tierra, todos consumidores y seres humanos con derecho a desarrollarse integralmente, en convivencia con las demás especies.

Palabras clave: dialéctica, economía, globalización, micromarketing, macromarketing, marketing neoclásico, materialismo histórico.

Clasificación JEL: A12, D11, F60, L10, L13, L22, M00, M31. 


\begin{abstract}
This article constitutes a theoretical-conceptual and descriptive effort to understand the connections among a marketing theory with real customer focus (the demand role) and the socio-cultural, ideological, political and economic aspects of the macromarketing authors that are assumed divergent of a micromarketing whose neoclassical origin has impeded its conceptualization from the science and its method; especially in this stage of the capitalism, where the globalization effects are manifested on the inhabitants of the planet earth, all consumers and human beings with right to be developed integrally, in coexistence with the other species.
\end{abstract}

Keywords: dialectical, economy, globalization, macromarketing, neoclassical marketing, historical materialism, micromarketing. 


\section{Resumo}

Este artigo constitui um esforço teórico-conceitual e descritivo para entender as conexões entre uma teoria do marketing com real foco no consumidor (o papel da demanda) e os aspectos socioculturais, ideológicos, políticos e econômicos dos autores do macromarketing que é simulado divergente de um micromarketing cuja origem neoclássica impediu seu conceptualização da ciência e seu método; máxime nesta fase do capitalismo onde são manifestados os efeitos do globalização nos habitantes da terra de planeta, todos os consumidores e seres humanos com direito ser desenvolvido integralmente, em coexistência com as outras espécies.

Palavras chare: dialético, economia, globalização, macromarketing, marketing neoclássico, materialismo histórico, micromarketing. 


\section{INTRODUCCIÓN}

Bajo la perspectiva teórica del presente trabajo sobre ciencia, en línea con los planteamientos de Bunge (1980 y 1985), el problema central se traslada al método; y al mismo tiempo, la interacción funcional entre hipótesis, leyes, teorías y modelos no puede ser ni lineal, ni dependerá del nivel de «agregación» $\mathrm{o}$ «reducción» con que abordemos el objeto de estudio, mucho menos, del camino o recorrido para abordar los constructos. Por ello, la inducción per se (de extendido uso en el marketing neoclásico ${ }^{2} \mathrm{y}$ los nuevos economistas neoclásicos) o la simple deducción, no son caminos absolutos o superiores por sí mismos, para confirmar la presencia o no de una in- vestigación científica; esa interacción es tan dialéctica como las conexiones del universo y exige ir o de lo general a lo particular, o viceversa, dependiendo de la naturaleza misma del fenómeno bajo estudio; es decir, partiendo siempre de la realidad, único punto posible cuando de la ciencia y su método se trata.

Exige igualmente la integración del nivel teórico con el empírico, línea de trabajo validada en la relación teoría-praxis que se refleja en la obra de $\mathrm{Marx}^{3}$; por ello, previo a cualquier experimento de validación empírica, existe la exigencia de contar con una verdadera hipótesis teórica (Popper, 1957 y 1967), que permita abordar correctamente las pruebas de investigación básica. Aspecto relevante

\footnotetext{
$2 \quad$ El artículo utiliza la expresión marketing neoclásico para identificar el concepto, modelo y esquema aplicativo de un marketing "clásico o tradicional", cuyos primeros trabajos datan de comienzos del siglo XX, que se estabiliza y difunde a finales de los años 50 y comienzos de los 60 con los trabajos de quien ha sido reconocido y llamado por su comunidad como "el padre de la mercadotécnica": Philip Kotler.

3 Karl Marx (1818-1883) escribió El Capital. Crítica de la economía política, entre 1864 y 1877; sólo viviría para ver publicado el Tomo I, en 1867 (ver referencia completa de su obra en la lista de referencias).
} 
si se tiene en cuenta que en el marketing neoclásico, los empiristas lógicos han puesto énfasis en la verificación gradual y creciente de planteamientos a los que llaman «teorías», insistiendo reiterativamente en la casuística y sus mecanismos estadísticos como único argumento probatorio (un cuestionamiento profundo se puede leer en Martínez, 2000); cuando en estos campos del conocimiento, sociales por encima de cualquier otro calificativo, el materialismo históricodialéctico como método, es una precondición básica del tratamiento científico.

La enseñanza académica, difusión a través de «gurús», conferencistas, consultores y demás expertos de moda, y el uso práctico (empresarial) del marketing real (no solo el académico), ha estado sumergido desde sus orígenes en concepciones teóricas neoclásicas o neoliberales (ofertistas y produccionistas), con énfasis en el marketing operativo de las $4 \mathrm{P}^{4}$, como administración de variables objetivo para asegurar a corto plazo ventas y utilidades individuales privadas, de las unidades microeconómicas llamadas empresas; su tendencia más clara en el mundo del micromarketing ha sido la utilización de fórmulas mágicas para lograr tales resultados empresariales. Así, la gerencia moderna parece seguir inmersa en el problema de antaño del modo de producción capitalista, que dio origen a la disciplina del marketing: cómo deshacerse de sus productos frente a los competidores, en contextos de competencia exacerbada y sobreproducción inercial estructural, frente a grupos amorfos de consumidores que aparecen pasivos, moldeables, influenciables, manipulables, etc.; unos que supuestamente reaccionan a la ley de Say, o ley de los mercados, según la cual toda oferta crea su propia demanda (Say, 1803) y los mercados tienden a equilibrarse estructuralmente de manera mágica e inercial.

Es a partir de las obras de Marx y Keynes, que en su momento contribuyeron al desbaratamiento de tal andamiaje conceptual y su cúmulo de sus supuestos, que es posible identificar la verdadera ley que alimenta una teoría seria del marketing: toda demanda crea su propia oferta. Y es evidente que el mundo necesita nuevas formas para abordar y entender la relación con los consumidores; las viejas idealizaciones clásico y neoclásicas que soportan el ancien régime no podrán en el futuro sostener de forma adecuada una teoría integral del marketing, con real foco en el consumidor; por ello, así como Marx pudo evidenciar los fundamentos macroeco-

\footnotetext{
$4 \quad$ El trabajo utiliza este término como el concepto de marketing más difundido y aceptado académica y empresarialmente desde que P. Kotler popularizó su uso en los años 60 del siglo XX; un marketing centrado en las 4P del mercadeo (en su versión original, Product, Price, Promotion y Place), también llamadas mix de marketing, mezcla de mercadeo o variables fundamentales del mercadeo; elementos operativos que focalizaron sus aspectos transaccionales y la visión técnica del problema táctico de los productores a corto plazo, dada su única razón de ser corporativa: maximizar las utilidades que se apropian individualmente.

5 Jean Baptiste Say (1767-1832), en su Tratado de economía política (1803) argumenta que la producción de bienes genera una demanda agregada realmente gastada, suficiente para comprar todos los bienes que se ofrezcan; por tanto, nunca hay sobreproducción generalizada en el sistema.
} 
nómicos que subyacen en el problema micro; o Keynes pudo puntualizar sobre los aspectos microeconómicos que cargan sobre los agregados, una tarea pertinente al desarrollo y avance del marketing está precisamente en poder vincular las conexiones entre eso que algunos pensadores llaman micromarketing (entendido como dirigido exclusivamente a las acciones de las unidades económicas, organizaciones, empresas, consumidores y hogares), y un macromarketing que pocos autores del management han podido enmarcar en el estudio de sus interrelaciones dialécticas con la sociedad; no solo las simples relaciones lineales causa-efecto que creen poder observar en sus análisis superficiales.

A finales de los años 90 del pasado siglo algunos escritores de macromarketing colocaban acento en cinco temas relevantes, en la relación entre marketing y: a) medio ambiente; b) justicia y ética; c) desarrollo económico; d) calidad de vida; y e) comportamiento de los mercados. Se añade uno que no sólo parece estar de moda, sino que en el actual contexto del modo de producción capitalista y sus más recientes crisis, adquiriría la mayor de las relevancias: la globalización. Pero no la globalización neoclásica-neoliberal de Fukuyama (1992, 2012), entendida como un «una fase final y perfecta del capitalismo», donde supuestamente «el marketing» logró empresas orientadas al mercado, y «el consumidor es el rey» (¿micromar- keting?); sino una histórica-real que da luces sobre el proceso surgido en el contexto imperialista de avance y desarrollo contradictorio del modo de producción capitalista, ligado a las necesidades de expansión de los flujos de capital más allá de las fronteras nacionales ( ¿macromarketing?); una que además de dos guerras mundiales e incontables guerras localizadas, ha conllevado la expansión y profundización de todas las relaciones sociales de producción, distribución, acumulación y consumo entre países ${ }^{6} \mathrm{y}$ así, ha generado mayor interdependencia entre naciones y culturas de diverso origen étnico-geográfico, en contravía de un modelo económico que sigue defendiendo el homo oeconomicus del siglo XVIII, de sesgo individualista, egoísta, hedonista y «del más fuerte», desde ambos campos: micro y macroeconomía.

Entender las conexiones entre una teoría integral del marketing (micro y macromarketing) con real foco en el consumidor y los aspectos socioculturales, ideológicos, políticos y económicos que plantean los autores del marketing neoclásico, es una tarea clave en este proceso de conceptualizar y trabajar el marketing desde la ciencia y su método; máxime en esta etapa senil del modo de producción capitalista, donde los efectos de la globalización no dejan de sentirse a lo largo y ancho del planeta Tierra, con consumidores que parecen perder su naturaleza social, su esencia y control como individuos-actores sociales vivos:

El objeto de estudio de la ciencia económica, no exclusivo de la macroeconomía o la microeconomía. 
seres humanos con el derecho a desarrollarse integralmente, y en convivencia armónica y pacífica con sus congéneres, y con todas las especies que habitan la tierra, pero estructuralmente marginados de tales decisiones.

Con todo ello, este artículo comienza abordando una discusión relevante acerca de las conexiones históricas entre la economía neoclásica y sus diversas escuelas $^{7}$, y un marketing, que sin asumirlo, posee estructural orientación y vocación teórica neoclásica. Posteriormente se plantea una visión teórica alternativa y de ruptura, desde la óptica del modelo dialéctico de marketing desarrollado por Garcés (1994), como único mecanismo social para garantizar la orientación y focalización de las organizaciones al mercado (al consumidor), o en términos generales, de la producción al consumo. Se profundiza posteriormente en los conceptos macromarketing y micromarketing, que al igual que en su ciencia básica (la economía), refleja otra de esas separaciones infundadas por su orientación teórica neoclásica. Y en el último acápite se develan algunas realidades y mitos sobre las posibles relaciones entre el marketing y la globalización, bajo el lente crítico de ambos conceptos. Se presentan al final algunas conclusiones y observaciones que surgen del análisis histórico-dialéctico realizado.

\section{CONEXIONES HISTÓRICAS EN- TRE ECONOMÍA Y MARKETING NEOCLÁSICOS}

Es necesario enfatizar en un hecho históricamente evidente que poco ha sido abordado en la literatura tradicional de marketing: la evolución del pensamiento económico y la manera como sus principales escuelas fueron dibujando una visión mecánica, estática y de equilibrio, del proceso económico y sus actores (oferentes y demandantes), con el consecuente enfoque produccionista-ofertista de mercados que se autorregulan y autosostienen de manera natural, para perpetuar su funcionamiento perfecto; todos ellos, elementos que dieron origen a las teorías del marketing neoclásico, y que han acompañado adecuadamente su producción literaria hasta hoy.

\footnotetext{
Es posible vincular los postulados del marketing neoclásico con las ideas psicológicas y económicas de la escuela matemática de Lausanne, con León Walras y Wilfredo Pareto a la cabeza; la escuela neoclásica de Cambridge, con Alfred Marshall y W. Stanley Jevons como máximos representantes; y finalmente, la escuela psicológica austríaca, cuyos principales exponentes fueron Karl Menger y Erik Bohm-Bawerk; estos últimos, a quienes se les puede considerar como sus reales "padres teóricos", conectores de la economía, la psicología y el marketing neoclásico (un tratamiento del tema en detalle se encuentra en Garcés, 2010).
} 
Tabla 1. Principales escuelas del pensamiento económico

\begin{tabular}{|c|c|}
\hline Mercantilistas (1500-1750): & $\begin{array}{l}\text { M. de Azpilicueta, T. de Mercado, J. Bodin, A. de Montchrétien, } \\
\text { W. Petty, etc. }\end{array}$ \\
\hline "Le Tableau Économique" & François Quesnay (1759). \\
\hline Fisiócratas (S. XVIII - La tierra) & François Quesnay, Anne Robert y Jacques Turgot (Francia). \\
\hline $\begin{array}{l}\text { Economía política clásica } \\
(1776 \text { a } 1870)\end{array}$ & $\begin{array}{l}\text { J. B. Say, } 1803 \text { (O=D), J. Bentham, A. Smith, D. Ricardo, } \\
\text { T. Malthus, John S. Mill, James Mill, etc. La Riqueza de las } \\
\text { Naciones, de A. Smith (1776). }\end{array}$ \\
\hline Teorías marxistas (integrales) & Karl Heinrich Marx (1818-1883). El Capital, T.1 (1867). \\
\hline $\begin{array}{l}\text { Teorías neoclásicas (micro } \\
\text { y macro) y escuela de las } \\
\text { expectativas racionales } \\
\text { (estanflación) }\end{array}$ & $\begin{array}{l}\text { 1. Marginalistas-Escuela Austriaca: W. S. Jevons; K. Menger; } \\
\text { E. Bohm-Bawerk; F. Edgeworth y B. Wieser (concepto de } \\
\text { tiempo continuo). } \\
\text { 2. Escuela de Lausana: L. Walras, } 1874 \text { (T. del Equilibrio } \\
\text { General); W. Pareto, } 1909 \text { (óptima asignación); K. Wicksell, } \\
\text { 1898 (T. del Capital). } \\
\text { 3. Teoría del equilibrio parcial: A. Marshall, 1890; y A. C. } \\
\text { Pigou. } \\
\text { 4. Monetaristas: K. Wicksell, I. Fisher y M. Friedman. } \\
\text { 5. Síntesis de "Keynes" - Modelo IS-LM: J. R. Hicks (1939) } \\
\text { y A. Hansen. } \\
\text { 6. Neoneoclásicos: P. A. Samuelson. }\end{array}$ \\
\hline Institucionalismo & $\begin{array}{l}\text { T. Veblen (1857-1929), J. R. Commons (1862-1945) y W. C. } \\
\text { Mitchell (1874-1948). La teoría de la clase ociosa, 1899, T. } \\
\text { Veblen. }\end{array}$ \\
\hline Teorías keynesianas (macro) & \begin{tabular}{|l} 
Jhon Maynard Keynes (1883-1946). La teoría general, 1936. \\
.
\end{tabular} \\
\hline $\begin{array}{l}\text { Teorías poskeyenesianas y } \\
\text { escuela del macrodesequilibrio }\end{array}$ & $\begin{array}{l}\text { 1. Neokeynesianas: J. Robinson, N. Kaldor, R. Harrod, E. D. } \\
\text { Domar, A. Eichner, J. Shumpeter, P. Davidson, E. Weintraub, } \\
\text { Minsky, etc. } \\
\text { 2. Neorricardianas: P. Sraffa, L. Pasinetti, P. A. Garegnani, etc. } \\
\text { 3. Neomarxistas: Michael Kalecki, P. Seezy, J. Steindl, A. Shaik. }\end{array}$ \\
\hline
\end{tabular}

Fuente: diseño del autor. 
La Tabla 1 muestra un sencillo resumen de las más importantes y representativas escuelas de economía, agrupadas por autores cuyos planteamientos han estado cerca, como en los paradigmas de Khun (1971); una revisión sintética a la evolución del pensamiento económico y sus diversas escuelas y teorías centrales, en contextos históricos concretos, exige buscar su relación con los orígenes y el objeto mismo de estudio del marketing.

Sin detenerse en las consideraciones de Platón acerca de la propiedad común, que lo era siempre y cuando se enmarcara en los derechos de las clases gobernantes del imperio, de naturaleza socioeconómica esclavista, poco es lo que puede decirse acerca del avance del pensamiento económico entre este y Aristóteles, a quien se le considera uno de los primeros defensores de la propiedad privada y sus bondades; su defensa acerca de la superioridad de esta frente a la común, por razones tanto de productividad como del cultivo de ciertas virtudes y condiciones morales que conlleva, sin lugar a dudas ha atravesado el pensamiento económico hasta hoy en día.

Todas las escuelas previas a la estabilización de las ideas liberales de Adam Smith y David Ricardo (los clásicos por excelencia), se apoltronaron en el argumental de Aristóteles; una de ellas, la primera en hacer su aparición histórica (los mercantilistas), defendiendo intereses de grupos de comerciantes en plena formación; y la otra (con Quesnay y demás fisiócratas), tratando de dar respiro a las clases terratenientes que pugnaban por la defensa de sus intereses sobre la tierra. Pero es evidente que ambas se movieron en la Europa de los siglos XVI, XVII y primera mitad del XVIII, en un período de transición histórica al que Marx identificaría como formaciones económicas precapitalistas, con relaciones feudales e incipientes Estados y soberanías nacionales en pleno proceso de conformación. Es importante resaltar de allí aquellos argumentos que hoy en día siguen esgrimiéndose como relevantes, simples ideas fisiócratas de la Francia del siglo XVIII: la existencia de una especie de ley natural, argumentada en sus orígenes divinos y bajo la cual el buen funcionamiento de los sistemas económicos estaría asegurado sin la intervención de los gobiernos (su pugna central con los primeros mercantilistas); de hecho, la esencia de tal doctrina ha dominado el pensamiento clásico en economía hasta nuestros días y permeado el marketing neoclásico, con sorprendente remozo de modernidad, bajo sus viejas expresiones: laissez faire, laissez passer (dejad hacer, dejad pasar).

Y claro, qué mejor herencia para el pensamiento económico clásico, cuyos trabajos se desarrollaron en una etapa de pleno auge económico del modo de producción capitalista, donde la Revolución Industrial estaba provocando enormes cambios sociales que promovían y reproducían la organización social alrededor del capital; es decir, un sistema de producción donde cada individuo debía buscar y procurar su propio e individual 
beneficio económico, como única garantía del bienestar colectivo a largo pla$z o$; si lo hacía, el sistema le premiaba, de lo contrario, este le castigaba. Allí, en el inexorable y maravilloso mundo de Adam Smith (como lo llamaría Marx), se necesitaba el hedonismo económico de Jeremy Bentham ${ }^{8}$, para que Smith configurara el molde de su homo oeconomicus: un ser social calculador, maximizador, frío, máquina insaciable de placer, siempre en la búsqueda de su propio y máximo nivel de bienestar individual; uno retomado posteriormente por los economistas neoclásicos (antiguos y modernos), que aportaron lo respectivo a la conformación de las primeras ideas de marketing; así, amarado de la mano invisible, se logra ensamblar tanto el modelo clásico como neoclásico (micro y macroeconómico), para asegurar la consistencia armónica, y de equilibrio a largo plazo de todo el proceso productivo; es decir, el sustento teórico de una supuesta superioridad y perpetuidad del modo de producción capitalista.

La puntada final al argumental clásico, que se entrelazaría con la posterior teoría del marketing neoclásico, es la llamada Ley de Say o Ley de los mercados, sintetizada así: toda oferta crea su propia demanda. Say (1803) describe un proceso lineal en el cual antes de que los consumidores puedan demandar bienes, los productores deben haber producido otros para intercambiarlos por los deseados; esto se traduce en un proceso de intercambio simple, estilo trueque (M-M'), con una relación causa-efecto entre la oferta y la demanda, donde el dinero es un simple velo de conexión entre los actos de compra y venta (MD-M'), y cuyo corolario sería simple: no pueden darse períodos prolongados de sobreproducción (visto desde Marx), o de subconsumo (visto desde Keynes), si el mercado, que se asume es perfecto, no sufre las interferencias indebidas de los agentes del Gobierno.

Pero algo extraño sucede en el último tercio del siglo XIX con la aparición simultánea de los trabajos de W. Stanley Jevons, Karl Menger y León Walras, entre 1871 y 1874 , quienes harían de las teorías subjetivas del valor el eje central del estudio económico. Aparece en escena la economía neoclásica, un conjunto de pensadores cuyos enfoques económicos de corte positivo desplazarían los análisis hacía la teoría de la utilidad marginal, insistiendo en el equilibrio mecánico y armónico entre la oferta y la demanda de largo plazo; y así, uno de los principales cambios corresponde al giro en el planteamiento del objeto y campo de estudio de la economía, entendida ahora como la ciencia de la escasez, con seres humanos racionales, tomando decisiones económicas de maximización, en contextos asociales y ahistóricos (casi como autómatas). 
Bajo tal lupa, la economía deja de ser una ciencia social para convertirse en una actividad racional y lógica, una técnica bonita y sofisticada, aplicable al estudio de la conducta óptima de los individuos, bajo comportamientos restrictivos (supuestos); ya no estamos hablando de seres sociales tomando decisiones mediadas (determinadas) y a la vez, determinando contextos de clase (desprovistas de su carácter social), sino aparentemente de manera independiente y desconectada, haciendo abstracción del marco histórico e institucional en el cual estas relaciones se desarrollan, plagadas de contradicciones; y algo aún más relevante: las leyes económicas, que defienden la superioridad del sistema libre de precios (precios del mercado), pasan a adquirir un carácter de óptimas, universales, irreversibles e insuperables; este, otro punto de gran relevancia a los orígenes mismos de las ideas del marketing neoclásico. Pero claro, se trata de un reforzamiento camuflado al conjunto de creencias que reflejan un determinado sistema de valores, con su respectivo soporte ideológico: la ideología neoliberal y su modelo económico y de gobierno, centrado en la contienda abierta entre desiguales, la globalización de los mercados y la perpetuación de este modo de producción (el capitalismo), bajo la supuesta superioridad organizativa (productividad y eficacia) y así, el llamado fin de la historia (Fukuyama, 1992 y 2012).

Sin embargo, es contra el enfoque de la economía política clásica (no contra las in- cipientes y nacientes teorías neoclásicas), que Marx se revela; su profunda crítica a procesos económicos unívocos, unidireccionados, conscientes, racionales y últimos, que constituían más un conjunto de creencias como reflejo del sistema de valores y su soporte ideológico (la ideología liberal), cuya teoría objetiva del valor adolecía de una falla estructural en la forma como Smith y Ricardo interpretaron el trabajo y sus relaciones con el capital, le llevó a realizar el más completo diagnóstico del funcionamiento endémicamente enfermizo del modo de producción capitalista.

Las teorías de Marx, expuestas en El Capital, ponen al desnudo las leyes económicas del movimiento de la sociedad moderna, permiten realizar un viaje de acercamiento progresivo a la realidad del modo de producción capitalista, desde altos grados de abstracción inicial (la mercancía), hacia grados cada vez menores y por ende, concretos, a fin de poder interpretar una realidad (los fenómenos económicos que rigen el proceso de reproducción ampliada del capital), cuyo nivel de complejidad es tan grande como para pretender acercarse directamente; es precisamente, en su esencia, un ejemplo de combinación dialéctica entre teoría y praxis; entre lógica e historia; entre observación teórica, constructos; y observación-validación empírica, hipótesis de investigación (Marx, 1867). Solo interesa aquí, por su relevancia en la reformulación de una sólida teoría del marketing, resaltar su aporte al tema, en relación con tres tópicos?: a) su pertinente

Los demás aportes de su obra, aunque relevantes y conectados al tema, no son base para la reformulación planteada; esto es, sus teorías de la producción, la distribución y la acumulación de capital. 
distinción entre valores de uso y valores de cambio; b) sus cuestionamientos a los planteamientos centrales de Say; y c) su teoría del consumo.

La distinción clara del doble papel del valor (valor de uso y valor de cambio), $\mathrm{y}$ de sus interacciones dialécticas, para poder entender el contexto en el que se desenvuelven las dinámicas e interconexiones entre demandantes y oferentes, intercambiando valores abstractos en los mercados, bajo la forma concreta de mercancías (productos tangibles e intangibles); pero igualmente, como una forma específica de colocar en entredicho la Ley de Say, donde pareciera como si la producción orientara de manera equilibrada, mágica e infinita, al consumo.

Así, para Marx «El valor de uso sólo toma cuerpo en el uso o consumo de los objetos...En el tipo de sociedad que nos proponemos estudiar, los valores de uso son, además, el soporte material del valor de cambio.» (Marx, 2000, p. 4). Es precisamente la cualidad de los bienes de poseer un valor de uso, al servir en la resolución concreta de necesidades humanas, lo que garantiza sus posibilidades y viabilidades como valores de cambio (esto es, un valor de cambio determinado por su valor de uso); sin embargo, no es posible en la sociedad capitalista (en cualquiera de sus etapas) transar bienes única y directamente en relación a sus valores de uso (totales o marginales), ya que lo que determinará su patrón de cambio (valor de cambio), además de su existencia potencial para el consumo (valor de uso), es la medida o cantidad en la cual se equiparen las cantidades de trabajo socialmente necesarias para sus producciones: un producto (tangible o intangible) puede representar valor de uso sin necesidad de poseer como tal, un valor de cambio, que se apropie individualmente (i. e., el aire); y de ello, solo existirá como valor de cambio si encierra valor de uso para el consumo, es decir, valor de uso social (i. e., un diamante).

Si tras la producción, en el proceso de circulación y consumo, no se realiza como mercancía (no da su salto mortal, como le llamaría Marx), no habrá materializado para su productor valor de cambio alguno; aún, con valor de uso, no representará valor de cambio y de ello, habrá destrucción de valor para el productor. Es importante insistir en este argumento, pues están presentes allí las bases teóricas del verdadero concepto de marketing; donde si existiera una ley que rigiera el movimiento de los mercados, sería inversa a Say; es decir, toda demanda crea su propia oferta. Dice Marx, refiriéndose al argumento de Say:

Nada más necio que el dogma de que la circulación de mercancías supone un equilibrio necesario de las compras y las ventas, ya que toda venta es al mismo tiempo compra y viceversa. Si con ello quiere decirse que el número de las ventas operadas supone un número igual de compras, se formula una necia perogrullada. Pero no, lo que se pretende probar 
es que el vendedor lleva al mercado su propio comprador. Venta y compra forman un acto idéntico...Nadie puede vender si no hay quien compre. Pero no es necesario comprar inmediatamente de haber vendido... Cuando cosas que por dentro forman una unidad, puesto que se completan recíprocamente, revisten al exterior una forma de independencia, y ésta se agudiza hasta llegar a un cierto grado, la unidad se abre paso violentamente por medio de una crisis. (Marx, 2000, p. 72 y 73)

Y de ello, Marx identifica el doble sentido y papel del consumo, en el proceso de circulación e intercambio de mercancías, como una crítica a la visión clásica del homo oeconomicus, determinado de manera natural y antropológica bajo una visión idealista (la conexión entre Hegel y Smith). Para Marx el mercado no es más que el lugar-tiempo-espacio (y claro, su contexto), en el cual surte efecto un proceso social de intercambio entre seres humanos, no siempre tan voluntario como los textos del marketing neoclásico suelen suponer; es «...la escena en la que se desarrolla el proceso de cambio...» (Marx, 2000, p. 65), donde tanto propietarios como consumidores acuden con intereses particulares de realización de valor. Los primeros no se interesan en sus mercancías en cuanto a sus valores concretos de uso; esto solo atañe a los intereses individuales de los segundos; para los primeros ...su mercancía no tiene un valor de uso inmediato. De otro modo, no acudiría con ella al mercado. Tiene únicamente un valor de uso para otros. Para él, no tiene más valor directo de uso que el de su encarnación de valor de cambio, y por tanto, medio de cambio...Por tanto, las mercancías tienen necesariamente que realizarse como valores (léase, valores de cambio) antes de poder realizarse como valores de uso. (Marx, 2000, p. 49) (nota resaltada fuera de texto)

Pero para poder engendrar y generar valor de cambio para sus productores, deben encerrar valor de uso para sus consumidores: «...para poder realizarse como valores, no tienen más camino que acreditarse como valores de uso.» (Marx, 2000, p. 49). Esa es la interacción dialéctica que subyace en la diada del valor, que se torna aún más compleja cuando se introduce el papel del dinero en el proceso, antes y después de que estas, las mercancías (productos tanto tangibles como intangibles), hayan sido producidas para la circulación y el consumo ${ }^{10}$. Es decir, mientras que el intercambio es para el productor un proceso social general (léase, objetivo), para el consumidor (incluyendo el consumo productivo que hacen los dueños de los medios de producción), es un proceso individual (léase, subjetivo), donde las mercancías sólo existen en cuanto a su función como productos (valores de

$\overline{10}$ En esta concepción los servicios son igualmente producidos y consumidos en la esfera de la circulación. 
uso); este es un elemento clave en el entendimiento de una teoría integral del marketing, que claramente se contrapone a las visiones neoclásicas del tema.

Finalmente, es en el seno de las teorías del equilibrio donde uno de los alumnos de Alfred Marshall se revela contra su escuela, demostrando que las interpretaciones neoclásicas sobre el capitalismo corresponden a idealizaciones y condiciones particulares (no generales), de difícil validación empírica. Keynes (1936) demuestra que es la demanda la que engendra renta, y al igual que Marx, vuelve a contradecir el argumento de Say, con profundas implicaciones de política económica: las variaciones de la producción suponen modificaciones en la utilización de la capacidad productiva existente y de ello, estancamiento; algo que se había podido verificar empíricamente con las secuelas de la gran depresión que se inició en 1929, que ya Marx había identificado medio siglo antes, con conclusiones y efectos de economía política algo diferentes. Sin embargo, es en sus demostraciones de cómo las fuerzas y dinámica de los mercados vienen dadas por el lado de la demanda (no por la oferta), que los pensadores del marketing debían acudir para refundar su paradigma.

A partir de allí, puede decirse que algunos autores poskeynesianos y neomarxistas han intentado sobrevivir a la arremetida del andamiaje ideológico reinante y predominante de las teorías neoclásicas o neoliberales; se les puede identificar con dos elementos centrales: a) la existencia real de mercados de competencia imperfecta, donde no hay mecanismos naturales que corrijan las deficiencias productivas; y b) la tendencia inherente y secular del capitalismo al macrodesequilibrio estructural. Para los poskeynesianos ${ }^{11}$, de relevancia clara a efectos de una teoría seria e integral del marketing, el mundo macroeconómico se caracteriza por la incertidumbre, hombres económicos ignorantes del futuro, $\mathrm{y}$ complejas interrelaciones contextuales entre las decisiones y acciones económicas de los diversos actores del mercado. Las constantes son: el desequilibrio estructural de los mercados, con crisis cíclicas inherentes de sobreproducción y en espiral creciente (hoy llamadas burbujas); sectores industriales bajo dinámicas de competencia imperfecta (monopolística), cuya tendencia estructural es hacia la concentración oligopólica; y asimetrías de mercado de todo tipo y nivel, tanto por el lado de la demanda, como por el de la oferta (información, barreras sectoriales, recursos estratégicos y capacidades empresariales, etc.).

El cuestionamiento de Marx sobre esa visión de la naturaleza humana egoísta, individualista, hedonista, de premio al interés individual y la búsqueda de la máxima satisfacción personal por encima de los intereses de la colectividad, es tal vez uno de los olvidos más patéticos

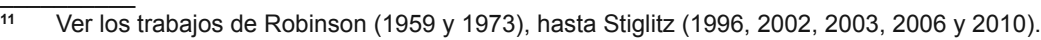


de la literatura neoclásica-mercadológica. Tan oprobioso aún, como el olvido estructural de quienes tratan de ver en Keynes modelos de eficiencia y armonía (certidumbre) en contextos de equilibrio (todos los pensadores del modelo ISLM, es decir, la síntesis revisionista que los neoclásicos hicieron del pensamiento de Keynes), e incluso, desconocen su aporte central alrededor de la incertidumbre como determinante central de la demanda en los procesos de inversión y acumulación de capital (el verdadero principio de la demanda efectiva). Para concluir esta parte, son necesarias dos observaciones finales: a) la definición de economía como una ciencia social; y b) la separación infundada entre microeconomía y macroeconomía.

En primer lugar, como aspecto teórico guía de este trabajo, se entenderá que la economía es una ciencia social, cuyo objetivo es el estudio contextual de las relaciones sociales reales de producción, distribución, acumulación y consumo, entre grupos de personas-seres humanos- cuyos intereses necesariamente aparecen en claro conflicto (clases sociales $)^{12}$; no so2lo en su accionar como oferentes (productores, vendedores, comercializadores, etc.) sino igualmente, en su calidad de demandantes (consumidores, compradores, clientes, etc.), y entre todos estos actores al mismo tiempo, máxime cuando acuden a intercambiar en algo muy concreto denominado el mercado.

En segundo lugar, la separación de los aspectos microeconómicos y macroeconómicos ha sido bastante cuestionada en la literatura, ${ }^{13}$ toda vez que no sólo se reconocen las complementariedades de ambos enfoques, sino que se puede demostrar como la línea de enseñanza predominante (las teorías neoclásicas y neoliberales) ha utilizado de manera soterrada tal separación para seguir cimentando su ideología acerca del funcionamiento y comportamiento económico de los actores del mercado (creencias). $\mathrm{Y}$ es notable cómo los modelos micro y macroeconómicos (todos de corte neoclásico) requieren del supuesto que cuestiona Robinson (1973): a menos que haya competencia perfecta en una economía, el equilibrio no puede existir; los supuestos llevan directamente a las conclusiones y estas no se darían sin la existencia de tal cúmulo de supuestos acerca de la realidad de los mercados y el comportamiento de sus agentes (simples y vulgares tautologías).

Bajo tal separación, mientras la microeconomía se dedica al análisis de la eficiencia de las unidades productivas (teoría de la elección), para cantidades dadas de producto, la macroeconomía se encarga del análisis de agregados de oferta y demanda, para determinar el

\footnotetext{
12 A diferencia del argumental neoclásico y neoliberal, para quienes la economía es la ciencia de la escasez, encargada de estudiar la manera como se pueden optimizar unos supuestos factores técnicos de producción, cuyas limitaciones se hayan establecidas entre las dotaciones escasas de tierra, capital y trabajo (el capital mantequilla del que hablara la Sra. Robinson, 1959).

13 A este respecto, ver la obra de Weintraub (1985)
} 
producto global. Pero cuidado, porque esta supuesta concreción de su campo de estudio solo utilizada en modelos lógico-abstractos, choca reiterativamente en la praxis de microeconomistas que suelen agregar en el ámbito de sectores industriales, ofertas y demandas homogéneas, de bienes económicos de todo tipo: productos tangibles e intangibles (servicios); fuerza de trabajo; e incluso, activos líquidos (formas de dinero).

Como el foco de sus análisis está en los precios relativos (que se determinan exógenamente, por lo que llaman las libres fuerzas del mercado), siempre el dinero termina cumpliendo un papel neutro, como una especie de «velo» de conexión entre compra y venta (M-D$\left.\mathrm{M}^{\prime}\right)^{14}$. Así mismo, tras la obra de Keynes (1936), lo que ha sido enseñado desde los años 40 es el ejercicio macroeconómico de Hicks-Hansen (el modelo ISLM) y por ello, es posible afirmar que en ambos casos (macro y microeconomía), hay un interés neoclásico y neoliberal profundo por validar las llamadas condiciones de equilibrio y armonía: óptimos de producción; niveles de eficiencia productiva y eficacia social; bienestar colectivo (macro), como subproducto del accionar racional, egoísta y maximizador de actores individuales en un mercado perfecto (micro); todos ellos, precisamente los input de las teorías del marketing neoclásico, a las que se hará referencia a continuación.

\section{¿DE CUÁL MARKETING SE ESTÁ HABLANDO AQUÍ?}

Los economistas llevan más de 200 años tratando de interpretar las conductas económicas de los seres humanos y la interacción entre psicólogos y economistas, en el tratamiento de estos temas, es tan antigua como estas dos disciplinas y el origen del intento humano por dar explicación y solución a sus problemas; de hecho, ha sido el centro de discusión micro-macro de las diversas escuelas del pensamiento económico y en tal debate, unos y otros han intentado enmarcarle como estrictamente racional o tipificarla en el otro extremo, como algo aleatorio y caótico, siendo que en la realidad observable del comportamiento humano definitivamente no aparece nunca en extremo, como lo uno o lo otro, como todos los eventos y comportamientos de la materia-energía en el espacio-tiempo (Hawking, 1988).

Este, de iure, es un problema social, altamente determinado por las condiciones económicas imperantes (de superestructura, o del macroentorno, en el lenguaje del marketing neoclásico); y su interrelación con los demás fenómenos que podrían enmarcarse en la clásica identificación de lo microeconómico. Por supuesto, su uso aplicado y normativo en exceso por parte de los gestores de las políticas empresariales, y más específicamente, por los analistas de la conducta

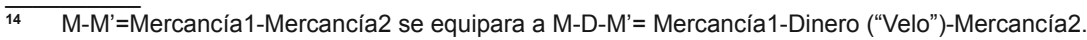


del consumidor y profesionales del marketing, no es sino el resultado del desarrollo de tecnologías que este modo de producción ha inventado para tratar de elevar o al menos mantener como sea la productividad: del trabajo, de la circulación de valores, de la realización de los mismos y la consecuente monetización de las mercancías (productos tangibles e intangibles), de la circulación del capital financiero, etc.

Así, facilitar las labores y procesos en la esfera de la circulación de mercancías era una tarea inaplazable y exigida, en una fase del capitalismo donde la acumulación intensiva de capital estaba aparejada con la exacerbada tendencia decreciente en la cuota de ganancia; un capitalismo que produce a plétora requiere de cada vez más sofisticados y modernos mecanismos para intervenir las relaciones asimétricas de intercambio entre productores y consumidores; y al mismo tiempo, para intentar administrar mejor las asimetrías crecientes entre productores, con sus proveedores, con sus socios estratégicos de negocio (canales), etc.; es decir, para tratar de $a u$ - torregular un mercado libre plagado de luchas desiguales, de masas desiguales de capital, en un mundo cada vez más interconectado y multidependiente; léase, globalizado.

Aunque tal como ya se ha indicado, las ideas originales e iniciales del marketing neoclásico deben ser olfateadas hasta los planteamientos económicos de sus padres teóricos neoclásicos (ver la $\mathrm{n}$. p. p. 7, p. 4-5; y la Tabla 1, p. 5), quienes trasladaron la discusión de la teoría del valor del trabajo objetivo a una basada en la utilidad subjetiva, es sólo hasta comienzos del siglo XX y con marcado énfasis, en el período entre las dos grandes guerras mundiales, máxime tras la gran depresión económica mundial y crisis de sobreproducción de los años 30 del pasado siglo, que pueden validarse las condiciones históricas reales y requeridas para que haga su aparición esta ciencia aplicada o tecnología ${ }^{15}$, llamada marketing.

El contacto teórico-conceptual entre economía, psicología y marketing (hoy llamado micromarketing) debe ser

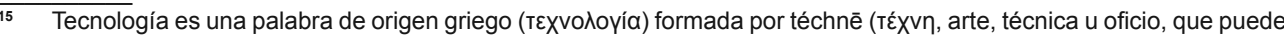

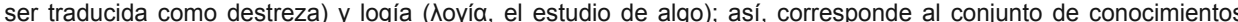
técnicos, ordenados científicamente, que permiten diseñar y crear bienes y servicios para facilitar su adaptación al medio ambiente y satisfacer necesidades esenciales y deseos de las personas. Por ello, se define tecnología como ciencia aplicada; es decir, la aplicación del conocimiento científico-de la ciencia- en un campo específico o disciplina, con el objetivo de mejorar la calidad de vida de los habitantes de la tierra-no solo humanos- y su sustentabilidad a largo plazo. Planteamiento epistemológico relevante, ya que permite distinguir entre ciencias básicas (i.e.: biología, física y economía) y ciencias aplicadas o tecnologías (i.e.: medicina, astronomía y marketing), frente a técnicas, artes u oficios con las que pueden interconectarse (i.e.: la publicidad). Se supera la visión reducida de tecnología centrada en sus resultados, objetos tecnológicos, artefactos, instrumentos de producción o de consumo, e incluso, simples productos del capitalismo contemporáneo; para el mismo Marx (1867) la tecnología no es "ni buena ni mala", y los juicios éticos alrededor de ella no tienen sentido, ya que no autodefinen la disposición y uso que se les dé-relaciones sociales de producción-, refiriéndose tanto a formas organizativas de los medios de producción, como a maquinas industriales; es ella misma capital, como facilitadora de productividad en la producción concreta de valores de uso y así, subordinada a la producción de plus-valores (y a la vez, subproductos del proceso).
} 
rastreado hasta allí, donde los neoclásicos asegurarían que el énfasis fuera puesto en los llamados agentes individuales (consumidores y empresas), para distraer adecuadamente de los planteamientos dialécticos de la obra de Marx sobre el enfrentamiento histórico entre clases sociales; igualmente, desplazando la atención a un tipo específico de bienes: los limitados o escasos (ya no bienes creados por y para el hombre, en su contexto social e interacción de clases); algo que necesariamente conllevaría la revisión del objeto mismo de estudio de la ciencia económica. El nuevo centro del análisis serían unas magnitudes lógicas, dadas y estáticas, de condiciones abstractas de: a) gustos o preferencias homogéneas de consumidores; b) dotaciones de recursos productivos igualmente homogéneos y perfectamente sustituibles; c) una tecnología dada, con estructuras de costos crecientes; y d) un problema económico circunscrito a la llamada asignación eficaz y eficiente de recursos escasos, en condiciones y características típicamente estáticas (equilibrio armónico).

Es evidente que sus raíces y orígenes teóricos estructurales hay que buscarlos en los modelos neoclásicos de la firma y las primeras teorías psicológico-económicas del consumo, de la escuela austriaca; pero es tras la realidad histórica de sobreproducción generalizada en los mercados mundiales (un problema del que debía preocuparse posteriormente el macromarketing), donde debe ubicarse su exigida aparición, como una necesidad empresarial real y orgánica; es posterior a ello que sus ideólogos y gestores, entre los años 50 y 60 del pasado siglo, lograron consolidar el paradigma de marketing que por las explicaciones dadas se ha calificado aquí como neoclásico.

A propósito de las múltiples versiones que se tienen acerca de los orígenes y el desarrollo histórico del marketing, un interrogante clave sería: ¿históricamente hablando, es posible validar la existencia del marketing empresarial real, no como una actividad suelta, desconectada del contexto de relaciones sociales con que se le ha identificado en el presente trabajo, o de cualquier otro tipo de práctica social con iguales intereses o fines, antes de la gran crisis de sobreproducción y la subsecuente gran depresión de los años 30 del pasado siglo? ¿Tiene sentido hablar de su presencia en la actividad empresarial o conceptual-académica, en un mundo donde las relaciones sociales de producción, distribución, acumulación y consumo, predominantes y determinantes eran precapitalistas? ¿En el contexto del comunismo primitivo de los primeros homo sapiens; en el mundo esclavista de la sociedad grecorromana de Platón y Aristóteles; en el orden feudal, con sus cortes, reyes, siervos de la gleba $\mathrm{y}$ derechos de pernada?

Ningún análisis sociohistórico serio sacaría avante tales hipótesis, salvo que se utilicen mecanismos idealistas (hegelianos) para resolver tales interrogantes; pero sin ir tan lejos en la historia, 
tendrá sentido igualmente plantearse el marketing en el contexto de las primeras etapas de evolución del modo de producción capitalista, donde aún (dado el bajo estado de avance y desarrollo de las fuerzas productivas), es posible validar la ecuación de Say donde toda oferta crea su propia demanda; es decir, bajo condiciones estructurales de permanentes excesos de demanda sobre oferta, y donde las dotaciones de recursos y las capacidades instaladas aún son insuficientes para atender los agregados de consumo (macromarketing). En suma, qué sentido tiene plantearse el marketing en una sociedad donde todo lo que se decida producir será automáticamente absorbido por los mercados (la demanda), que se acomodará pasivamente a sus condiciones de producción; esto es, todas las formaciones económicas precapitalistas e incluso, las primeras etapas de evolución y transformación del actual modo de producción a las que Marx se referiría como procesos de acumulación simple (no sostenida), que validaban permanentes tales excesos de demanda sobre oferta; allí definitivamente nunca fue requerido el marketing.

Una vez se ha aclarado este aspecto, es a esta realidad histórica, en el avance y desarrollo del modo de producción capitalista, como un fenómeno objetivamente observado y medible, a la que se hará aquí referencia como algo generalizable, extensible y necesario socialmente; algo que se llamará marketing; esta nueva tecnología o ciencia aplicada que surge a partir del afianzamiento de la fase expansiva mundial del capitalismo (globalización de la producción), con sus procesos autosostenidos de crecimiento, acumulación e incrementos de productividad del trabajo; es allí que cobra sentido el desarrollo de tal fuerza productiva, una transformación histórica que tiene clara identificación preliminar en el período comprendido entre finales del siglo XIX y comienzos del XX.

Pero, como toda categoría social en permanente proceso de evolución y cambio, como fuerza productiva viva de la sociedad, que ya ha adquirido una dinámica propia de movimiento y cambio (incluso, moviéndose en contravía del statu quo que plantean las relaciones sociales de producción imperantes, su régimen de acumulación y su marco regulatorio), no hay ningún argumento que permita soportar la hipótesis de que necesariamente deberá morir con el capitalismo, tal como lo piensa Fullerton (1988). Es mucho más probable que le supere en vida y que adquiera una nueva dinámica en los procesos de intercambio de unidades de valor, centrándose cada vez más en el foco de resolución integral y holística de las verdaderas necesidades de los seres humanos (todos ellos consumidores y a la vez, productores), en contravía incluso del ancien régime; esto es, una demostración histórica clara de la relevancia del marketing en la sociedad poscapitalista y en la construcción misma del socialismo del siglo XXI.

La American Marketing Association le definía en los años 60 como «...el 
resultado de la actividad empresarial que dirige el flujo de bienes y servicios desde el productor hacia el consumidor o usuario»; así las cosas, el marketing tradicional de las 4P se fundó centrado en la visión de quienes se llevaron su conceptuación en los años $60^{16}$ y 70 hacia los instrumentos operativos de la mezcla mercadotécnica (equivocadamente definidas por muchos como estrategias), donde el protagonista central son unas variables fundamentales que parecen adquirir vida propia y relevancia, y alienaron del problema a su verdadera esencia: el consumidor. $Y$ aunque en los siguientes 20 años se re-escribieron tantas versiones de las 4P, como autores del marketing y modas empresariales fueron surgiendo (Garcés, 2003, 2005, 2005 y 2006), ello no colaboró al anclaje de este paradigma a la verdadera ciencia y a la orientación de las organizaciones al mercado y al consumidor (Garcés, 2010).

Posteriormente, entre los años 80 y 90 , la discusión sobre el fondo estratégico del problema marketing, donde subyace la conexión con el consumidor y sus necesidades, quedaría relegada por una superficial línea de trabajos interesados en demostrar que el marketing podía extenderse a todo tipo de portafolios, de organizaciones (privadas, públicas, mixtas, etc.), y de experiencias de intercambio (a corto y largo plazo), donde existan unas unidades interesadas en ofrecer y otras en demandar ideas, causas, actividades políticas, actividades culturales, actividades religiosas, etc.; y en general, cuanta casuística fuera apareciendo y permitiendo poner de moda algún tema que su descubridor eligiera. La disciplina cayó en el hondo abismo de las modas superficiales (ver Garcés, 2003, 2005 y 2006).

Anderson (1982 y 1983) afirmaba que el marketing solamente podría adquirir el carácter de ciencia si se dedicaba a estudiar los fenómenos del intercambio desde la perspectiva de todos los actores y participantes en el proceso, y no solo desde la óptica de la empresa o práctica gerencial, algo que se había constituido en la práctica académico-empresarial más extendida: así mismo, cuando Hunt (1991) cuestionaba las teorías que logró identificar Bartels (1988), planteando que no cumplen con los requisitos de una teoría general, estaba ubicando el centro del problema, identificando cómo esta disciplina adolecía (y adolece aún) de serios problemas estructurales de fragmentación, de identidad y de credibilidad, caminando entre dos grandes extremos: a) o sufre de excesos de generalización, sin fundamentación rigurosa en la ciencia (Sarabia, 1999); o b) o se enfrasca en pobres y tautológicas disertaciones de elevada nano-especialización, sin conexión alguna entre sus partes (Martínez, 2000).

16 Es una época prolija en la publicación de manuales de marketing, tales como los de McCarthy (1960), Buskirk (1961), Cundiff \& Still (1964), Stanton (1964), Kotler (1967), y Phillips \& Duncan (1968). 
Las discusiones que venían planteando Day y Wind (1980), Webster (1981, 1988, 1992 y 1994), Day y Wensley (1983 y 1988), Carlzon (1987), Day (1990, 1992, 1994A, 1994B, 1995, 1996 y 2000), y Day y Van den Bulte (2002); unidas a los argumentos de Grönroos (1983, 1989, 1990, 1994 у 1995) y Gummesson (1987, 1988 y 1991), configurarían una nueva línea en el entendimiento del marketing, que recuperaría al consumidor y al proceso de construcción de relaciones con el mismo, a largo plazo, y presionaría en agosto de 2004 la publicación de una nueva definición de marketing por el grupo directivo de AMA: «Marketing es una función de la organización y un conjunto de procesos dirigidos a crear, comunicar y distribuir valor a los clientes, y a dirigir las relaciones integrales con los clientes, de forma que se beneficie mutuamente la organización y sus públicos de interés» (AMA, 2004). En esta «última»" ${ }^{17}$, quedan latentes los siguientes elementos: a) el marketing es, por encima de todo, una función organizativa, al igual que la contabilidad, las compras, etc.; b) se define en función de un conjunto de procesos; c) desaparecen por primera vez del escenario las 4P, e igualmente, los conceptos de intercambio y satisfacción; d) las nuevas palabras clave (las de moda), que sustituyen las extintas, son valor y $C R M$ (de la sigla en inglés, customer relationship management); y finalmente, e) se habla de beneficios mutuos.
Para que se pueda validar que el marketing utiliza el método científico, hablando de ciencias sociales o naturales, básicas o aplicadas, se debe demostrar su capacidad explicativa y aplicabilidad en todos los contextos posibles (casuística), donde se identifiquen procesos sociales de intercambio de unidades de valor, entre actores de la diada del mercado, con intereses asimétricos diversos y casi siempre en conflicto; y además, cuya capacidad explicativa sea demostrable históricamente hablando, en el contexto de aquellos diversos modos de producción concretos (economía mercantil simple, capitalismo, socialismo, etc.), donde fuera posible verificar su presencia como categoría social. Esto es, un marketing que dé respuesta a aquella parte del estudio de las relaciones sociales de producción, distribución, acumulación y consumo, por la cual no pudo responder adecuadamente en su momento el paradigma dominante de su ciencia básica (la teoría económica neoclásica de la firma); más exactamente, la microeconomía con fundamento neoclásico. De allí su desenfoque en el uso de teorías al garete de la coyuntura y las modas empresariales, en la casuística propuesta por los autores de la literatura mercadológica, elementos que solo han logrado alejarle de su verdadera esencia y desarrollo como ciencia social y aplicada.

Así, lo que debería discutirse es si es o no una ciencia; y si lo es, definir bien su naturaleza; y si es una ciencia social (que

\footnotetext{
Definición modificada nuevamente en el 2007, así: "Marketing is the activity, set of institutions, and processes for creating, communicating, delivering, and exchanging offerings that have value for customers, clients, partners, and society at large"; y hay "cambios" más recientes.
} 
definitivamente lo es), con todo lo que ello implica, parecería redundante hablar bajo cualquier pretexto, de un supuesto marketing social (que si pareciera incorporar los temas del macromarketing) y otro que pudiera no serlo (el antiguo micromarketing); pero más importante aún, si la satisfacción de las necesidades del consumidor ha sido, es y será el elemento central cuya dinámica e interacción es objeto de entendimiento y resolución por esta joven disciplina, no tiene sentido hablar de unas etapas del «marketing» donde no haya existido orientación al consumidor o, al mercado; lenguaje difuso, poco serio, que le ha restado credibilidad. Con todo ello, ahora se puede plantear el reto de definirle amarrada a una teoría económica integral y humana, indicando que el marketing es un paradigma de la ciencia en pleno proceso de desarrollo, donde cada vez se identifican más los elementos que le acercan a la ciencia, de aquellos predominantes que le separan de ésta y le han dado mayor énfasis a planteamientos cercanos a la metafísica, lo esotérico o cualquier otro enfoque pseudocientífico.

Se puede entonces visualizar el marketing como una ciencia social aplicada (es decir, una tecnología), que se concreta en el estudio de aquellos aspectos contextuales que determinan las relaciones sociales entre oferentes y demandantes, para garantizar los procesos de intercambio que se generan en los mercados; es decir, se circunscribe a la identificación de algunos de los aspectos socio-económicos, culturales, demográficos y del compor- tamiento humano (entre ellos los psicológicos), que determinan la producción y el consumo, para asegurar el intercambio de unidades de valor entre oferentes y demandantes (la diada); no necesariamente de equivalentes, ni en contextos armónicos o de equilibrio, tal como lo plantean los enfoques neoclásicos.

Como todas las ciencias sociales, utiliza la historia como su método central de análisis (información de la relación de intercambio), con el fin de construir modelos de comportamiento del consumidor que permitan aprender permanentemente de las relaciones que se establecen en los mercados, entre productores y consumidores; y al entender cómo se comportan en el tiempo sus factores determinantes, puede ir definiendo verdaderas estrategias (de crecimiento y participación de mercado, a corto plazo; de posicionamiento, a mediano plazo; y de competitividad, a largo plazo), así como tácticas comerciales (marketing operativo), que posibiliten elaborar modelos y mecanismos de medición y predicción, bajo el principio central de incertidumbre en los mercados y no garantía automática de equilibrios entre ofertas $\mathrm{y}$ demandas.

Resultado de lo anterior, como cualquier otra ciencia (básica o aplicada), trabaja con márgenes de error posibles de establecer y medir, bajo niveles razonables de riesgo, y probabilidades asociadas de éxito en la predicción, mayores a las que brindan la intuición o el azar puro (probabilidades 50-50); 
así, un modelo integral de marketing, construido desde la ciencia, debe verificar los componentes y elementos de su dialéctica y dinámica. Aunque no es objeto del presente trabajo el profundizar en este tema, ya que desborda sus límites y objetivos, la Figura 1 permite resumir el modelo de visión dialéctica del marketing planteado por Garcés (1994); una explicación detallada del tema puede encontrarse en Garcés (2003, 2005, 2006, 2010 y 2014).

Modelo Dialéctico de Marketing

Jorge E. Garcés C., 1994 - 1995

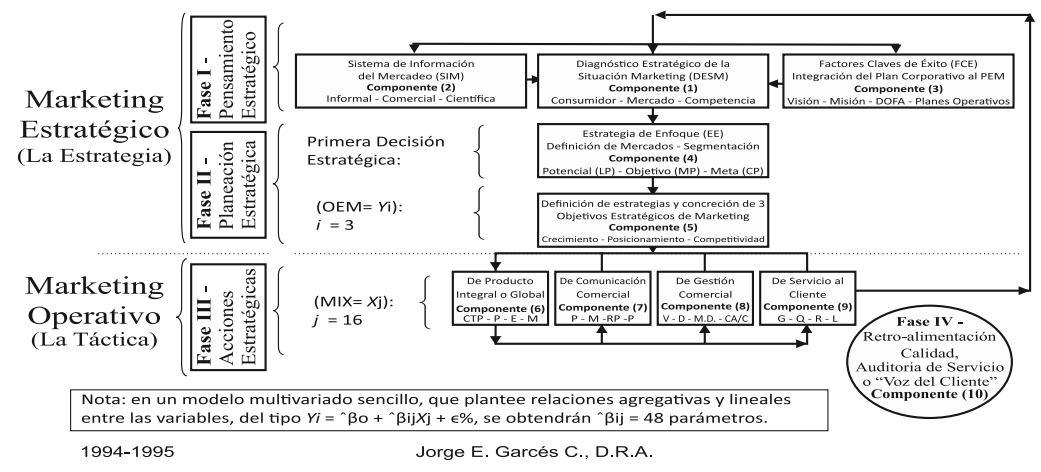

Figura 1. Modelo dialéctico de marketing.

Fuente: diseño del autor, a partir de Garcés (1994).

La Figura 1 resume el modelo gráfico de marketing bajo una visión dialéctica del proceso descrito; un modelo integral construido desde la ciencia y su método, donde se verifican las fases, componentes, elementos e interacciones funcionales de sus diversas partes, visualizadas desde una perspectiva integral $u$ holística, misma a la que se hará referencia a partir de ahora como visión dialéctica del marketing ${ }^{18}$. Bajo el modelo dialéctico de marketing (MDM) que describe la Figura 1, el marketing estratégico (fases
I y II, componentes 1 al 5) precede al marketing operativo (fases III y IV, componentes 6 al 10) pero a la vez le incluye; exige la visualización e identificación de su viabilidad desde las fases de pensamiento estratégico (fase I) y planeación estratégica (fase II); es decir, bajo este planteamiento teórico se enfatiza en dos aspectos:

1) El marketing estratégico -la estrategia-, solo es posible allí donde se identifica y atiende la relación dialéctica existente

18 En una visión dialéctica, que incorpora la dinámica -siendo en sí misma movimiento-, lo que se intenta identificar es el movimiento de cada uno de los elementos o partes que la componen, y entender el escenario real en el cual se va desarrollando la construcción de relaciones con clientes a largo plazo; el concepto de rentabilidad con el que se revisen sus logros supera o desborda la visión pecuniaria, individualista y de corto plazo, del paradigma neoclásiconeoliberal (ver una explicación detallada del tema en Garcés 2010 y 2014).

64 
entre pensamiento estratégico (fase I del MDM, con los componentes 1 al 3 de la Figura 1), planeación estratégica (fase II del MDM, con los componentes 4 y 5), y acción estratégica o táctica (fase III del MDM, con los componentes 6 al 9); aspectos explicados más adelante.

2) Aunque existen temas estratégicos de corto plazo $^{19}$, el verdadero marketing estratégico no puede focalizarse en las acciones estratégicas de corto plazo, bajo el uso de las diferentes variables operativas de la mezcla de marketing, énfasis utilizado por el marketing neoclásico; desde la perspectiva aquí asumida, son simples tácticas u operaciones que constituyen sus variables independientes; y la estrategia, como conjunto de variables dependientes del mismo, exige planteamientos adicionales de mediano y largo plazo (ver abajo la n. p. de p. 19); aspecto que también se amplía más adelante.

El MDM de la Figura 1 explica el desarrollo sistémico de los procesos comerciales de pensamiento (fase I), planeación (fase II) y acción estratégica (fase III); estas últimas, las tácticas, operaciones, actividades y tareas necesarias y suficientes para conquistar, acercar, seducir y retener el mercado -la demanda-, con portafolios de productos o soluciones -la oferta- que satisfagan las necesidades de los consumidores y así, consolidar la permanencia y el crecimiento rentable de cualquier tipo de organización en dicho mercado; es decir, el desarrollo, monitoreo y seguimiento a la historia de una posible relación mercado/producto a largo plazo, asegurando la retroalimentación permanente mediante la operación funcional de un sistema de calidad, auditoría de servicio o «Voz del cliente» (fase IV, componente 10).

Algo que solo es posible estableciendo relaciones sostenibles en el tiempo con grupos de consumidores que adquieren la tipificación de clientes, en cuyo proceso el consumidor es tanto punto de partida como de llegada; se trata de procesos para identificar, crear, comunicar y entregar unidades de valor: valor de uso o subjetivo, por el lado de la demanda; y valor de cambio u objetivo, como sustento material de la capacidad para crear valor al productor, por el lado de la oferta. Es imposible hacer una presentación extensa del MDM; por ello, solo se realizan algunas anotaciones sobre las diversas fases, componentes y elementos constitutivos de la Figura 1, explicados en extenso en Garcés (1994, 2003, 2005, 2005A, 2006, 2010 y 2014). Se evidencian en la fase de pensamiento estratégico en marketing (fase I), tres componentes clave para resolver:

\footnotetext{
En este modelo multivariado es la estrategia de crecimiento y participación de mercado a corto plazo, que se concreta y a hace explícita para su medición en el tiempo con el primero de los tres objetivos estratégicos de marketing (OEM) indicados en el componente 5 de la Figura 1; las otras dos estrategias y OEM son posicionamiento a medio plazo y competitividad a largo plazo, marcando una clara diferencia con el modelo univariado del marketing neoclásico, que focaliza en las ventas a corto plazo.
} 
1. El diagnóstico estratégico de la situación Marketing (DESM), componente 1 de la Figura 1, como condición sine qua non de los procesos de planeación estratégica (fase II, componentes 4 y 5) y de la acción estratégica o táctica (fase III, componentes 6 al 9), que minimice las probabilidades de error (un nivel de riesgo probabilístico, que no es lo mismo que suponer ausencia de riesgo).

2. La construcción de un sistema de información del mercado (SIM), componente 2 de la Figura 1, como único mecanismo continuo y estructural de valoración y garantía de difusión de la voz del mercado al interior de las organizaciones para asegurar procesos de medición permanente y así, una disminución creciente de la toma intuitivoemocional de las decisiones. Y

3. La definición de los factores claves de éxito (FCE), componente 3 de la Figura 1, una técnica que garantiza el alineamiento de la estrategia organizacional ${ }^{20}$ al plan estratégico de marketing, como un mecanismo adicional de presión interna para la orientación al mercado y al consumidor.

En la fase II de planeación estratégica de marketing (componentes 4 y 5 de la Figura 1), el primer paso del proceso siempre debe ser identificar con claridad, a partir de la fase diagnóstica pre- via, los grupos estables de consumo con los que exista interés de construir relaciones mercado-producto, en sus diferentes contextos de relacionamiento y unidades de tiempo; esto es, la primera decisión estratégica en marketing que se muestra en el componente 4 de la Figura 1: una estrategia de enfoque (EE); allí la segmentación del mercado no es la estrategia, es simplemente una técnica, instrumento o herramienta de las ciencias económico-administrativas que debe ser usada en el proceso para poder determinar en sus tres dimensiones ${ }^{21}$ los mercados a atender a largo (mercado potencial), a medio (mercado objetivo) y a corto plazo (mercado meta).

Y el segundo paso, que consiste inicialmente en la definición cualitativa de las tres (3) estrategias marketing: estrategia de crecimiento a corto plazo (utilizando como referente teórico a Ansoff, 1968), estrategia de posicionamiento a mediano plazo (con referente teórico en Ries \& Trout, 1990; y Ries \& Ries, 2000) \& estrategia de competitividad o construcción de ventaja competitiva a largo plazo (Porter, 1979, 1982 y 1990). Tras ello, es indispensable su cuantificación con indicadores pertinentes de logro, eficacia o resultados, que permitan su medición y seguimiento en el tiempo; esto es, su concreción como variables dependientes (Yi) del MDM (variables de salida u output), que constituyen la forma explícita de medición de los resultados de la es-

20 Estrategia de negocios, estrategia corporativa, planeación estratégica integral, etc.

21 Luego de su identificación cualitativa, un mercado debe ser cuantificado simultáneamente en tres dimensiones: número de prospectos $(P)$, número de unidades de producto $(Q)$ y valor monetario $(\$)$. 
trategia comercial a través de sus tres (3) indicadores, los objetivos estratégicos de marketing (OEM), componente 5 de la Figura 1: OEM de crecimiento y participación de mercado a corto plazo (Y1); OEM de posicionamiento a mediano plazo (Y2); y OEM de competitividad a largo plazo (Y3).

Finalmente, la fase III de acción estratégica de marketing (componentes 6 al 9, Figura 1) o marketing táctico-operacional-, que comprende las tácticas, operaciones, acciones, actividades, tareas, etc. ${ }^{22}$, las cuales deben verificarse en función de su mayor a menor nivel de relevancia y contribución a los verdaderos OEM anteriormente definidos ${ }^{23}$. Estas tácticas son las variables independientes $(\mathrm{Xj})$ del MDM (variables de entrada o input), que solo deberían ser definidas cuando exista claridad sobre lo que se espera lograr; han sido identificadas utilizando y reorganizando algunos de los elementos de la mezcla del marketing neoclásico, componentes 6 al 9 de la Figura 1 (MIX), y se muestran aquí agrupadas como factores estadísticos o grupos de variables de control a fin de que puedan ser fácilmente comparables:

1) El producto integral o global (componente 6 de la Figura 1), que eng- loba las decisiones e inversiones en características técnicas del producto (X1), precios (X2), empaques (X3), y marcas (X4).

2) La comunicación comercial (componente 7 de la Figura 1), correspondientes a publicidad (X5), merchandising (X6) y otras formas de comunicación directa ( $\sin$ los medios), relaciones públicas con enfoque comercial (X7), y promoción (X8) como descuentos e incentivos al consumidor final, a cortísimo plazo.

3) La gestión comercial (componente 8 de la Figura 1), en relación a canales tradicionales de comercialización o ventas (X9), canales de distribución físico-geográfica (X10), campañas de marketing directo (X11), y canales virtuales -alternativos o complementarios- de ventas o distribución (X12). Y finalmente,

4) El servicio al cliente (componente 9 de la Figura 1), con campañas y programas reactivos y proactivos para: garantías y servicios de posventa (X13); manejo de peticiones, quejas, trámites y reclamaciones de los clientes (X14); planes de reparación, retención y recuperación de clientes (X15); y programas de mantenimiento, satisfacción y loyalty -fidelidad y lealtad- de clientes $(\mathrm{X} 16)^{24}$.

22 El marketing neoclásico y el management les han reiterado erradamente como "estrategias".

23 En un modelo sencillo, mediante la identificación de sus correlaciones matemáticas.

24 Nótese que todo el tiempo, en relación a esta variable se hace referencia a clientes; es decir, de todo el conjunto posible de consumidores que tengan interacción con la oferta, aquella parte que se ha cualificado como tal y se ha transformado de simple comprador inicial, eventual, fortuito, etc., a una relación objetiva de cambio, medida en función de su antigüedad, su frecuencia y su valor económico en el tiempo; lógicamente, como valor de cambio para el oferente, una medida de su valor presente neto. 
Puede concluirse del MDM que la diferencia entre los objetivos estratégicos y los operacionales está dada por la relación dialéctica existente, ya definida, entre estrategia y táctica: los objetivos operacionales están subordinados a los estratégicos, pero así mismo, los estratégicos incorporan, orientan desde su concepción y plantean la viabilidad misma de los operacionales; mientras los estratégicos corresponden a las variables de salida del proceso (output), los segundos corresponden a las de entrada del mismo (input); es decir, instrumentalmente hablando, los primeros (los OEM) siempre serán las variables dependientes del MDM (Yi; donde $\mathrm{i}=3$ ); en tanto que los segundos (el MIX), corresponderán a sus variables independientes $(\mathrm{Xj}$; donde $\mathrm{j}=16$, para la síntesis aquí realizada).

Siendo esta una ciencia aplicada, además de los modelos gráfico (Figura 1) y verbal (su explicación conceptual detallada), se requiere de su representación resumida como modelo matemático (ampliación del tema en Garcés, 2010 y 2014); una abstracción y síntesis de la realidad, que permita simplificar el fenómeno a observar para su categorización, estudio y medición en el tiempo. Para ello, puede utilizarse un sencillo sistema matricial de regresión lineal simple, tal como el que se indica a continuación ${ }^{25}$ :

$\mathrm{Yi}={ }^{\wedge} \beta \mathrm{o}+{ }^{\wedge} \beta \mathrm{ij} \mathrm{Xj}+$ Error

$\mathrm{Y} 1+\mathrm{Y} 2+\mathrm{Y} 3={ }^{\wedge} \beta 0+{ }^{\wedge} \beta 1(\mathrm{X} 1 \mathrm{Y} 1)+{ }^{\wedge} \beta 2(\mathrm{X} 2 \mathrm{Y} 1)+\ldots+{ }^{\wedge} \beta 16(\mathrm{X} 16 \mathrm{Y} 1)+{ }^{\wedge} \beta 17(\mathrm{X} 1 \mathrm{Y} 2)+$ ${ }^{\wedge} \beta 18(\mathrm{X} 2 \mathrm{Y} 2)+\ldots+{ }^{\wedge} \beta 32(\mathrm{X} 16 \mathrm{Y} 2)+{ }^{\wedge} \beta 33(\mathrm{X} 1 \mathrm{Y} 3)+{ }^{\wedge} \beta 34(\mathrm{X} 2 \mathrm{Y} 3)+\ldots+{ }^{\wedge} \beta 48(\mathrm{X} 16 \mathrm{Y} 3)+\in \%$

Tal como se indicó en la descripción verbal y sintética del modelo, siempre existen tres variables dependientes (Yi; $\mathrm{i}=3)$ y sólo para la síntesis aquí realizada, se han planteado 16 independientes $(\mathrm{Xj} ; \mathrm{j}=16)$; las primeras corresponden a los indicadores de logro de las tres estrategias del MDM, explícitas a través de los OEM (Y1, Y2 y Y3); y las segundas, al posible conjunto de tácticas o MIX a utilizar (X1 a X16), listadas en sus cua- tro grupos de variables (conglomerados o factores estadísticos); cuyos elementos fueron ya identificados en forma resumida para cada una de ellas.

En esta explicación matemática del MDM, ^ $\beta$ o es el parámetro que indica la proporción de resultados (OEM) que no pueden ser explicados por las tácticas de marketing usadas (MIX), es decir, factores totalmente exógenos, alea-

\footnotetext{
En mercados reales y para cualquier relación mercado/producto a estudiar, las variables del modelo no siempre esgrimirán una condición de relacionamiento lineal y agregativo, tal como la indicada aquí solo para sintetizar el problema; tampoco es razonable asumir siempre ausencia de colinealidad y multicolinealidad entre estas, elementos de comodidad en el modelaje, más que de validez empírica. Igualmente, es probable que las variables mencionadas, tanto los OEM $(\mathrm{Yi})$ como el MIX $(\mathrm{Xj})$, presenten covarianzas entre ellas y para su modelación podría ser apropiado establecer las relaciones a través de un sistema de ecuaciones estructuradas, donde puedan fijarse condiciones de causalidad menos restrictivas, tema que desborda el presente artículo.
} 
torios e incontrolables que cargan sobre las estrategias; y los ^ $\beta \mathrm{ij}$ corresponden a 48 parámetros o estimadores lineales in-sesgados que permiten identificar las correlaciones matemáticas existentes en el tiempo, entre cada par de variables dependientes (OEM) e independientes (MIX); finalmente, õ $\%$ identifica un grado o nivel aceptable de error, propio del ejercicio mismo de modelaje. Es el margen de error ( $\tilde{\mathrm{o}} \%)$ obtenido en una regresión, asociado a la cantidad y calidad misma de las series de datos en número de años utilizadas para obtener los parámetros de la regresión; en este caso, las matrices correspondientes a las series anuales con los indicadores de resultados obtenidos en las tres estrategias (OEM) y sus correspondientes inversiones monetarias en las 16 variables de la mezcla de marketing (MIX) ${ }^{26}$.

De la capacidad de los analistas o científicos del marketing para estudiar, modelar y entender tales relaciones dependerá la posibilidad de obtener una mayor probabilidad de logro en la implementación de los planes. Afianzar tales relaciones a largo plazo entre productores y consumidores es una tarea del marketing en su casuística, sea de aplicación local, nacional o internacional; aspecto que no podrá desarrollarse sin un seguimiento continuo a la historia de tales interacciones y relaciones de intercambio, no sólo mediado y guiado por objetivos pecuniarios y de maximización de utilidades, con apropiación individual a corto plazo.

Así, el marketing que construye modelos puede ayudar a establecer mejores conexiones en los mercados para posibilitar una verdadera utilización eficiente de los recursos productivos de la sociedad, en función de las necesidades reales de los seres humanos; sin embargo, la gerencia neoclásica sigue inmersa en el cómo deshacerse de productos, frente al cómo descubrir y acercarse a quienes realmente los necesitan, aquellos en los que encuentran el valor esperado. La sociedad requiere de nuevas formas para abordar la relación con los consumidores; hoy, de forma cada vez más marcada, producto es mucho más que un conjunto de características técnicas, sean tangibles o intangibles; y su precio nunca se valida separado de él; y este último, en el capitalismo, no se forma bajo interacciones pasivas oferta/demanda y mercados de competencia perfecta, en empresas que calculan «puntos de equilibrio financiero», sino en mercados con estructuras sectoriales asimétricas, y tendencias de concentración monopólica y oligopólica.

El marketing neoclásico le ha apostado reiterativamente a las leyes del azar, a la casualidad, y a la intuición; la evidencia histórica/empírica ratifica un indicador bastante pobre, con tan solo 1 de cada 10 casos probadamente acertados. De allí la urgencia de implementar procesos cien-

26 Por ejemplo, para un histórico de 10 años, sería una matriz-vector de $19 * 10$ (190 datos), para obtener los 48 parámetros (` $\beta \mathrm{ij}$ ) en la regresión, con un excelente nivel de grados de libertad. 
tíficos de análisis del mercado que permitan cumplir los tres grandes objetivos estratégicos planteados en el MDM (los OEM), como su variables dependientes; con probabilidades más altas y márgenes de error más pequeños que los brindados por el azar puro. Hacer predicciones sobre el comportamiento de los mercados es uno de los objetivos centrales del planteamiento científico en marketing; sin embargo, no debe olvidarse que no se indagan factores de producción; se estudia el comportamiento de seres humanos, en sus relaciones sociales de consumo; esto es, todos los elementos determinantes de la demanda y la forma como carga sobre la oferta; si la psicología, sociología y antropología proporcionan información relevante al marketing, es necesario seguir avanzando en esa línea. Y el bajo nivel de conceptualización, la falta de claridad estratégica, el exceso coyuntural, la prueba o ensayo sin medición alguna -sin aprender de la experiencia-, han sido una norma evidente del estilo empresarial y del marketing neoclásico aquí cuestionado.

El mundo y «su modernidad» requieren nuevas formas de abordar la relación con los consumidores; la Ley de Say no va a ayudar por mucho tiempo más. En la mayoría de las empresas del tercer mundo, aún algunas grandes que operan a nivel transnacional, no se dispone de presupuestos apropiados para investigación de mercados y el desarrollo de nuevos productos, mucho menos para implementar sistemas de monitoreo permanente a los niveles de satisfacción de los consumidores: clave central de los procesos de marketing. Hace más de 60 años Drucker (1954) afirmó que el objetivo de las empresas era crear clientes; decía:

Es el cliente quien determina lo que es un negocio, sólo el convierte los recursos económicos en riqueza, las cosas en bienes. Lo que el negocio cree que produce no es de importancia primordial para su futuro. Lo que el cliente piensa que compra, lo que él considera valor es decisivo, determina lo que es el negocio y si él mismo ha de prosperar. El cliente es el cimiento de un negocio y el motivo de su existencia.

No se puede permitir continuar improvisando al vaivén de la coyuntura o la moda, y alimentando en organizaciones de todo tipo la idea de que como se trata del comportamiento de las personas (y este es supuestamente impredecible), lo mejor es «actuar rápido» $\mathrm{y}$ aprovechar la gran experiencia de quienes vienen manejando el negocio, o de algunos consultores «gurús». El bajo nivel de conceptualización, la falta de claridad estratégica, el exceso coyuntural, la prueba o ensayo sin medición (aprender de la experiencia), son normas bastante notorias del estilo del marketing neoclásico; máxime en el contexto latino de administración (parafraseando a Sallenave, 1995), que no sólo le imprime ciertos sesgos de inmadurez y bajo desarrollo al marketing de las organizaciones, sino que se refleja en otras de sus actividades, 
tales como: a) la improvisación en la planeación de presupuestos de ingresos y gastos; b) las deficiencias en los procesos de selección del personal, sobre todo en los cargos de dirección que tienen relevancia técnica; c) la poca o nula orientación al trabajo en equipo (algo que se refuerza en los procesos de selección, muy orientados a la evaluación de las calidades individuales y aptitudes en general, para garantizar estrellas en el territorio; d) la creencia de que son los jefes quienes trazan el norte (casi como señores feudales) y sus tribus deben seguirlas al pie de la letra, sin salirse de la línea (casi como siervos de la gleba), algo que se traduce en bajos niveles de empowerment: empoderamiento y facultamiento.

\section{MACROMARKETING Y MICRO- MARKETING: OTRA SEPARACIÓN NEOCLÁSICA INFUNDADA}

Luego de plantear la discusión sobre micro y macroeconomía, es pertinente revisar la aparición de estas dos tendencias al interior del marketing; es decir, cómo pudo existir un inicio y evolución de algo llamado marketing, que se centró en problemas y aspectos operacionales propios y exclusivos del contexto de los intereses de los inversionistas privados (micromarketing), a espaldas de las grandes macrodeterminaciones (antes de los años 70); y cómo y por qué, bajo el marketing social de comienzos de los años 70 (Kotler \& Zaltman, 1971), surgió un interés por revisar la conceptuación misma del paradigma (su ampliación a otras actividades y temas), que parecía haber dejado por fuera de la joven disciplina algunos aspectos clave y relevantes del macromarketing.

De hecho, los primeros argumentos de lo que actualmente anda de moda bajo el nombre de responsabilidad social empresarial (ver el trabajo de Garcés, 2007, 2009 y 2012), tienen precisamente su origen aquí, en las ideas de Lavidge (1970), Kelley (1971), Dawson (1971), Feldman (1971), y Spencer y Moinpour (1972), quienes proponían que el director de marketing añadiera a las clásicas 4P los siguientes elementos: a) consumerismo; b) limpieza (ecología, anticontaminación y reciclaje de productos); y c) conservación de recursos (prudencia, eficiencia y justificación de recursos gastados); incluso, algunos de ellos insistían en la conformación de entidades que velaran por los intereses sociales, $y$ hasta llegaron a hablar de la necesaria intervención gubernamental; una herejía antineoclásica, seguramente tomada de las obras de Keynes, pero nunca reconocida así.

Tal vez los primeros en trabajar abiertamente el concepto con el término macromarketing fueron Moyer (1972), y Bartels y Jenkins (1977), luego de 1976 cuando la American Marketing Association organizó varios seminarios sobre el tema, que confluirían a la creación del Journal of Macromarketing en 1981. En el trabajo de Bartels y Jenkins (1977) se indica que bajo tal nombre se venían revisando aspectos en una gama muy amplia de sentidos, 
para designar sistemas y grupos de instituciones relacionadas con el problema microempresarial del marketing: canales de distribución, instituciones privadas $\mathrm{y}$ públicas, asociaciones, gremios, etc., que no habían sido inicialmente contemplados en los componentes centrales del micromarketing (entendido hasta allí como un marketing para individuos y empresas de acumulación privada de capital).

Pero es indispensable resaltar que este «olvido» teórico-conceptual obedecía abiertamente a la fuente original de nacimiento del marketing y su punto de partida: las teorías microeconómicas neoclásicas; y al hecho conexo de que los marketineros creen que existe una única línea de pensamiento en teoría económica (de Smith a Ricardo, los clásicos; pasando por Walras a Marshall, los primeros neoclásicos), desconociendo o mejor, eliminando por incompatibilidad teórica los aportes de los trabajos pioneros y revolucionarios que permitieron dar saltos cualitativos relevantes en el debate económico; y claro, en el desarrollo de una teoría macroeconómica alternativa: la crítica de la economía política clásica de Marx y el ataque a los postulados neoclásicos de Keynes. Lógicamente, a los desarrollos posteriores de las líneas marxista y pos-keynesiana y el surgimiento de paradigmas alternativos a la explicación de las interacciones micro macroeconómicas, como por ejemplo los trabajos de Piero Sraffa, que darían como resultado el surgimiento de la escuela neorricardiana.
Pero la línea de desarrollo y separación entre micro y macromarketing es bien reciente, pues data de comienzos de los años 70 del pasado siglo, en tanto que la discusión entre micro y macro economía es un debate que se origina a finales del siglo XIX y se siembra de raíz tras la publicación de La teoría general de Keynes, considerado hoy padre de la macroeconomía moderna. El primer intento serio de separación del enfoque de micromarketing fue el trabajo realizado por R. Moyer (1972), para quien mientras el micromarketing se enfocaba únicamente a los temas empresariales, el macromarketing debería abordar su relación con el contexto general del sistema económico en su conjunto; paradójicamente, esto parece más una argumentación de Marx, que de un administrador de empresas neoclásico, del siglo XX. Posteriormente, Hunt (1982) plantearía que mientras el micromarketing se dirige exclusivamente a las acciones de las unidades económicas (organizaciones, empresas, consumidores y hogares), el macromarketing se enmarca en el estudio de las interrelaciones (causas-efecto) entre sistemas de marketing y sociedad, $\mathrm{y}$ viceversa.

Debe concordarse con Quintanilla (2002) cuando afirma que a partir de allí la producción científica sobre temas relacionados con macromarketing ha sido bastante pobre; e incluso, la razón central se haya precisamente en la manera como esta joven disciplina nació altamente sesgada por la influencia microeconómica neoclásica y su énfasis en 
los elementos que relacionan las decisiones empresariales sobre el producto (de oferta), en subordinación de las decisiones del consumidor (de demanda); es decir, con la creencia en el funcionamiento perfecto de los mercados y la llamada Ley de Say.

Pero no es posible estar de acuerdo con el mismo autor cuando le adjudica a Katona (1963) el origen de los temas centrales de la psicología económica; por ejemplo, al indicar que su trabajo permitió establecer cómo la conducta económica depende de la capacidad y voluntad de los individuos para consumir o ahorrar, cuando cualquier estudiante de primer semestre de economía sabe que es precisamente ésta una de las más importantes contribuciones de Keynes (1936) al pensamiento económico: la columna vertebral de la obra de Keynes es el principio de la demanda efectiva; $y$ allí, parte de la definición teórica de los dos lados del proceso macroeconómico en la ecuación de ingresos (el consumo y el ahorro), logrando establecer precisamente que es una situación psicológica determinada (la propensión marginal a consumir o su inverso, a ahorrar), la base explicativa de cómo los seres humanos distribuyen sus ingresos entre consumo y ahorro.

En términos generales, no es posible rebuscar en los trabajos de algún marketinero de los últimos 50 años el origen de la insistencia en los temas de la demanda; ese cambio de perspectiva y énfasis en los temas del proceso económico jalonado por el lado de la demanda se dio de facto en los trabajos de Marx, al desbaratar todos los postulado básicos de las teorías económicas clásicas; y de iure, en Keynes, al hacer lo suyo con los planteamientos en los que fue educado en Cambridge (las teorías económicas neoclásicas). Ambos, Marx y Keynes, contribuirían a su manera al desbaratamiento del andamiaje conceptual del supuesto central que subyace en unas y otras: la ley de Say, o ley de los mercados. Ley que en los inicios neoclásicos del marketing le haría su daño al enfoque dado a los procesos comerciales: la producción, el producto, la labor del vendedor, la comunicación publicitaria, las marcas, y cualquier otra acción que soterradamente siempre ha estado plagada de producción, fuerza de la oferta, espíritu emprendedor empresarial, etc.; todas ellas, simples manifestaciones de un mundo que aún no acaba de aceptar el papel que tiene la demanda en la dinámica de estos procesos de relaciones, dentro o fuera del modo de producción capitalista.

Por ello, no debe extrañar que pueda y deba establecerse una conexión entre los orígenes de una interpretación económica integral (macro y micro), con énfasis en los elementos sociales, como la de Marx; el nacimiento de la macroeconomía moderna con Keynes; y los primeros trabajos de un marketing alternativo a la tradicional visión centrada en los aspectos micro-económicos: el macromarketing de los años 70; donde parecía vital rescatar conceptos como la calidad 
de vida de los ciudadanos. A finales de la década de los 90 el macromarketing ponía acento en por lo menos cinco temas relevantes: a) marketing y medio ambiente; b) marketing, justicia y ética; c) marketing y desarrollo económico; d) marketing y calidad de vida; y d) marketing y mercados.

\section{REALIDADES Y MITOS SOBRE LA RELACIÓN ENTRE MARKETING Y GLOBALIZACIÓN}

¿Cuál es la relación existente entre marketing y globalización? ¿Qué es la globalización, desde la perspectiva económica? ¿Cuándo comenzó realmente el proceso y por qué se ha venido agudizando en los últimos años, a una tasa creciente? ¿Cuáles son sus principales implicaciones en diferentes tipos de soberanías nacionales? ¿Qué se puede concluir de todo este proceso?

Superada en este trabajo la visión del marketing neoclásico, que lo circunscribiría al «conjunto de operaciones por las que ha de pasar una mercancía desde el productor hasta el consumidor» (Economía Planeta, 1980, p. 491); y de globalización, que lo dibujaría como un proceso acelerado de dependencia de la vida cotidiana y doméstica de los seres humanos a un conjunto de fuerzas económicas y políticas que van más allá de los estados nacionales, convirtiéndose en una fase final y perfecta del capitalismo ${ }^{27}$, se puede abordar el conjunto de sus interacciones que necesariamente pasa por el entendimiento de esos aspectos que hoy en día se trabajan desde el llamado macromarketing (su punto de conexión). Y es importante resaltar aquí que el término globalización ha sido utilizado en los últimos 20 años por pensadores neoclásicos o neoliberales del management y el marketing como una más de sus modas literarias; es decir, una ideología, especie de receta y consigna empresarial, que reivindica la puntada final al proceso ilimitado de acumulación sostenida de capital a lo largo y ancho del planeta, bajo el sueño de siempre de los capitalistas e inversionistas: la acumulación sin protestas (Anderson, 1992); una especie de sociedad universal sin clases sociales, donde los obreros están virtualmente inermes a resistir los dictados económicos de quienes poseen el control económico del planeta (Hirsh, 1995).

Es, al entender de sus defensores ${ }^{28}$, la fase final, última y perfecta del capitalismo, cuya transformación cualitativa le ha permitido dotarse de mecanismos mágicos e invisibles de autorregulación, cuyo funcionamiento está más allá y por encima del individuo; los seres humanos, no importa de qué clase social sean (si es que estas se consideraran en el análisis), parecen estar asistiendo al fin de la historia de Fukuyama (1992 y

27 En la tradición más reaccionaria denominada por Fukuyama $(1992,2012)$ como "el fin de la historia".

28 Una nueva versión de economistas, mucho más vulgares que los identificados por Marx en su momento, ya que en su pensamiento y actividad, estos administradores y marketineros son neoclásicos y neoliberales, sin siquiera saberlo o defenderlo abiertamente. 
2012) y la dinámica del sistema ha llegado a un punto muerto, donde la sociedad perfecta ha logrado por fin eliminar todo aquello que le impedía florecer: el supuesto triunfo de la libertad individual sobre cualquier tipo de opresión colectiva (léase libertad económica de quienes pueden ejercerla); y la democracia capitalista mostrada con remozo como el sistema político del ordenamiento universal. Pero, ¿es esa la globalización real de hoy?; ¿no será que al enfrentar al análisis histórico de este modo de producción aparece una globalización feroz que refleja grandes contradicciones, que le hacen insostenible? Sin tal revisión es imposible dar luces acerca de sus conexiones con el verdadero marketing integral, sin importar si le rubrica o no bajo el término de macromarketing.

Bajo la lente de Marx, la globalización sería la forma particular como se muestra el avance y desarrollo de los factores de la producción; es decir, la manera concreta como las fuerzas productivas presionan y erosionan las relaciones sociales de producción capitalistas, aunque nacidas de su interior como modo de producción concreto; una de cuyas manifestaciones más claras es el avance incontenible de la composición orgánica del capital, a contrario sensu de la evolución de los valores reales (objetivos) y la materialización de plusvalías, con la resultante tendencia decreciente en las cuotas de ganancia medias de los inversionistas; no en sus masas absolutas (Marx, 1867); y de allí, Bonefeld (1998) describe acertadamente cinco elementos definitorios de este proceso:

1. El significado y la creciente importancia de la estructura financiera y de la creación global de crédito, que lleva al dominio de las finanzas sobre la producción (ver Lenin, 1917, 1985); donde el capital financiero se ha convertido en una fuerza independiente, cuyo creciente poder ha construido una especie de superestructura financiera que presiona la productividad.

2. La importancia en aumento de la 1lamada estructura del saber, donde el conocimiento es uno de los más importantes factores de la producción.

3. El aumento en la velocidad de los ciclos de obsolescencia tecnológica y su proceso de transnacionalización creciente, donde el énfasis industrial está puesto en sectores basados en el conocimiento, con fuerte ritmo de innovación y rápida introducción de nuevos productos.

4. El ascenso e incremento de los oligopolios, que aparecen en la forma de corporaciones multinacionales, resultado de la fusión, adquisición, joint venture, alianza estratégica o cualquier otra modalidad que les permita a las ya hoy corporaciones locales transformarse en globales y transnacionales, so pena de desaparecer; al lado de ellas, grandes bancos transnacionales con poderes e influencia superiores a los de sus estados nacionales, o sus economías locales. 
5. La globalización de la producción, del conocimiento y de las finanzas, donde los antiguos estados nacionales se retiran como posibles reguladores, para eliminar las ineficiencias que ello causa al mercado libre; y unido a esto, una globalización del poder político, apareciendo una especie de estructura de autoridad plural asociada a las Naciones Unidas, el G7, el G8, etc. Los viejos Estados nacionales se van transformando en una especie de Estados de competencia.

Se está hablando de un mundo globalizado ¿para quién? para los Estados de competencia, que son cabezas de bloques económicos; para corporaciones globales y transnacionales, con suficiente poder económico (recursos y capacidades estratégicas) para imponer monopólicamente sus condiciones productivas y sus productos al consumidor, a lo largo y ancho del planeta; para los 100 hombres más ricos del planeta Tierra $^{29}$. O para los países más pobres de América Latina, Asia y África; para los millones de micropymes que constituyen claramente el anti-Pareto de las empresas del tercer mundo, registradas en sus respectivas cámaras de comercio; para los miles de millones de habitantes (posibles consumidores), que no pueden ser incorporados en la ecuación de demanda de la mayoría de los productos que se llevan a los mercados mundiales, no porque no tengan necesidades, sino porque no poseen capacidad de compra (la ecuación de demanda en el contexto del actual modo de producción); e incluso, en la más reciente paradoja de las crisis estructurales del capitalismo, para los millones de ciudadanos de clase media típica (norteamericana y europea), que indignados dejan ver claramente su malestar con esta globalización.

Los neoclásicos o neoliberales, defensores a ultranza de la llamada globalización, pregonan que es fuente de libertad individual; que asegura la libertad económica y garantiza un sistema libre de ordenamiento político, donde la democracia capitalista se convierte en el fin mismo de la historia; se asegura así el viejo sueño de la burguesía mundial: la globalización como inicio de un proceso sostenido de acumulación de capital trasnacional sin protestas. Si en algún lugar geográfico no se acepta el proceso de producción o de sus condiciones, el capital decide trasladarse a aquellos lugares donde estas ineficiencias y fricciones no se presenten (áreas más favorables, con mejor clima de inversión); los gobernantes de turno, ligados a intereses plutocráticos de burguesías criollas, se asegurarán de que así sea, firmando cuanto tratado internacional de libre comercio puedan ${ }^{30}$, consolidando el papel de las naciones más

\footnotetext{
Todos ellos, miembros pertenecen al $1 \%$ de Wall Street (el santuario contemporáneo de la especulación a todo nivel), tal como les denominan los indignados del movimiento occupy, y a quienes se les acusa de no pagar impuestos, de recortar empleos, de realizar todo tipo de fraudes hipotecarios y bursátiles, y de recibir bonificaciones escandalosas por cualquier tipo de actuación especulativa en los mercados.

3o Una reciente muestra de ello está en Colombia, donde los últimos dos gobiernos (Uribe y Santos) han profundizado los vínculos e intereses con el capital financiero mundial mediante la firma y entrada en vigor del Tratado de Libre Comercio con los EEUU, con la Unión Europea, y hasta con Corea del Norte.
} 
pobres como vertedero de los excedentes de capital y sobrantes de mercancías de las potencias mundiales, condición requerida en su intento por salir del atolladero generado por sus crisis de sobreproducción y su conexo, la tendencia estructural de caída en sus tasas medias de ganancia.

Para ello, la burguesía siempre ha actuado en función de la racionalidad del capital; esta, como categoría social (no un factor de la producción), desconoce fronteras, razas, credos, edades, géneros, o cualquier otro elemento definitorio de los antiguos Estados nacionales, importantes en su momento para socavar el viejo régimen feudal. Pero el proceso de expansión capitalista a nivel mundial (o globalización) no es algo que socialmente se halla iniciado en los últimos veinte años, como piensan algunos marketineros y escritores del management; ¿o es que el capital descubrió el mercado mundial a finales de los años 80 del siglo pasado?; si fue así, ¿dónde estaba antes el capital?, como cuestiona Bonefeld (1998). Dos guerras mundiales, cuyos orígenes comerciales parecen ser olvidados reiterativamente, hablan de ello y de la participación de los actores centrales de Wall Street en el manejo económico financiero mundial, expedientes rotundos de la historia: una gran depresión en los años 30 del pasado siglo (crisis de sobreproducción) y múltiples coletazos financieros, bursátiles y de sectores industriales clave, entre los 70 (dos shocks petroleros), los 80 (crisis de las deudas externas), los 90 y comienzos del siglo XXI (con desfalcos como los de Enron, Madoff, Stanford, Lehman Brothers, AIG; burbujas como las de las empresas puntocom y las hipotecas sub-prime; $\mathrm{y}$ falsos informes sobre la deuda griega, como los de Goldman Sachs), también así lo demuestran.

Lo que sí es claro es que en las actuales condiciones del orden internacional la defensa del proceso globalizador asegura un mecanismo para afianzar la muy liberal $\mathrm{y}$ antigua idea de que el proceso de acumulación de capital pude darse sin crisis, siempre y cuando los trabajadores $^{31}$ se acostumbren a ser puros factores de la producción de ciudadanía universal (global); así, se asegura la no observación de relaciones sociales entre personas y se elimina cualquier tipo de resistencia de clases, al proceso de acumulación de capital. Cuando se habla de dueños de los medios de producción, se hace referencia a aquellos que poseen el capital como masa crítica, es decir, que tienen el poder real o potencial de convertirse en actores del proceso de acumulación sostenida, ahora más exigente dadas sus condiciones de transnacionalización y globalización; no es un escenario apto para vendedores ambulantes o prestadores de servicios irrelevantes en el tercer mundo.

Así las cosas, hay que entender que la globalización es en primer lugar,

\footnotetext{
Todos aquellos que no son dueños de sus propios medios de producción y estos, son una condición social-material de su actuación real como inversionistas en procesos productivos de largo plazo.
} 
globalización de la producción; es decir, profundización de la fase trasnacional del capitalismo. Y como proceso histórico que surge en el contexto de desarrollo del modo de producción capitalista, claramente ligado a las necesidades de expansión de los flujos de capital más allá de las fronteras nacionales, conlleva a la expansión y profundización de todas las relaciones sociales de producción, distribución, acumulación y consumo entre países; de esta forma, su exigido corolario es la generación de mayor interdependencia entre naciones y culturas de diverso origen étnico-geográfico, en contravía incluso de un modelo económico que sigue defendiendo la filosofía del homo oeconomicus del siglo XVIII, de claro sesgo individualista, egoísta, hedonista $\mathrm{y}$ de supremacía del más fuerte. Esta es una profundización adicional de sus múltiples contradicciones sociales. Como todos los procesos histórico-sociales, este modo de producción seguirá avanzando en medio de la dialéctica de sus contradicciones; por ello, los estudiosos de las ciencias económico-administrativas, sea cual sea su condición o lugar, deben aprender a leer con claridad sus señales y discernir sobre las posibilidades de intervención que poseen los países, los sectores industriales, las empresas, las organizaciones, los consumidores, y cualquier otro actor que se vea afectado en el proceso.

Desarrollos tecnológicos, innovaciones, e incrementos de productividad, así como mayores reducciones en distancias geográficas y crecimientos casi ilimitados en las comunicaciones virtuales, han planteado un avance tal al modo de producción reinante, incluso bajo condiciones impensadas, y resultados cuyo cálculo aún está por hacerse; un mundo de producción pletórico en medio de la más profunda de las miserias del grueso de la humanidad. El resultado más visible y cuantificable ha sido un aumento vertiginoso del proceso mundial de acumulación de capital (con sus fenómenos cíclicos de sobreproducción en casi todas las ramas productivas), en medio de abundante pobreza y miseria: una contradicción insalvable.

Algunos literatos del management y del marketing neoclásico siguen pensando que la globalización es un proceso que se inició en los últimos años; máxime para países como Colombia que se abrieron indiscriminadamente al modelo neoliberal aperturista a comienzos de los 90, y en los últimos tres gobiernos han estado profundizando en la aplicación de tales políticas macroeconómicas para sus nacionales; esta fijación ahistórica, de origen estrictamente neoclásico (en lo económico) y neoliberal (en lo político), está ligada a la supuesta nueva validación de condiciones de perfección en los mercados; esto último, un supuesto teórico imposible de verificar a nivel empírico en el capitalismo de comienzos del siglo XX y cada vez menos en el actual: las llamadas condiciones de equilibrio en los mercados son, como lo define Robinson (1959 y 1973), teóricamente insostenibles y empíricamente imposibles bajo la actual competencia oligopólica y a muerte por los mercados mundiales. 
Vale la pena realizar algunas anotaciones finales sobre las relaciones entre marketing y globalización, dado que los adalides de la liberalización a toda costa son igualmente defensores de la idea de acabar en los países pobres con cualquier vestigio de participación del estado en la economía, y por ende, de las privatizaciones a ultranza, la destrucción de la empresa pública y la fijación onírica de convertirlo todo en mercancía (productos tangibles e intangibles). Dicen sus gestores, en su argumentación, que por su naturaleza las empresas privadas son eficientes $y$ en ellas no existe corrupción; así, el mejor aporte de un gobierno a sus nacionales es acabar con su sector público y permitir a los privados intermediar toda operación (léase, negocio privado); por ello, a lo largo y ancho del planeta los neoclásicos/neoliberales lograron reconvertir incluso sectores estratégicos para el desarrollo social y grandes conquistas de derechos universales constitucionalmente protegidos, en grandes negocios de facturación individual; entre los más sentidos están: los servicios públicos domiciliarios básicos (acueducto-agua potable, alcantarilladotratamiento de aguas residuales, energía eléctrica-gas natural y telefonía básica); la salud; la educación en sus diferentes niveles; y el manejo de los recursos de ahorro pensional individual y de largo plazo de los trabajadores.

Fedesarrollo (Fundación para la Educación Superior y el Desarrollo), una entidad privada sin ánimo de lucro que se autodefine como «independiente para el estudio de las mejores políticas económicas públicas en Colombia», enfatiza en una supuesta línea causal entre globalización y democracia, donde la democracia garantiza y promueve la libertad económica per se; es decir, asegura el fortalecimiento del sector privado mientras se elimina la presencia del sector público; y donde la libertad política se interpreta como sinónimo del fortalecimiento a los grandes partidos políticos tradicionales que soportan tal democracia, so pena de erosionar y desquebrajar aún más la unidad nacional. A contrario sensu de lo que indica el mismo proceso económico en sí, sus dirigentes caen en la normal contradicción que encierra la filosofía liberal, cuando trata de dar explicación científica y justificación social a un proceso cuya evaluación se realiza en un plano puramente técnico (léase neutralidad valorativa), a fin de ocultar las relaciones sociales de producción que dan dinámica a tal proceso; lógicamente, se trata del viejo proceso de acumulación capitalista, cuya fase de expansión transnacional (globalización) es tan antiguo como el origen mismo del capital (Wallerstein, 2007).

\section{CONCLUSIONES Y OBSERVACIO- NES FINALES}

El marketing pudo haber sido conceptuado desde el principio de forma integral, es decir, incorporando ambos aspectos (macro y micro) que subyacen en el problema de cómo asegurar el enfoque de la producción al consumo y a la resolución real de las necesidades de 
los habitantes del planeta tierra; no solo las básicas y reproductivas que aseguran nuestra especie, sino todas las relevantes al avance mismo de las fuerzas productivas en el contexto de relaciones sociales de producción vigentes, o en las sociedades que se han de construir en el futuro: el socialismo del siglo XXI. Esta parece ser la afrenta más relevante de la humanidad en esta fase de producción con acumulación intensiva de capital en contextos mundiales y transnacionales, llamada globalización.

Pero como se deriva del presente escrito, tal nacimiento estaba condenado al fracaso dado el enfoque neoclásico y neoliberal del paradigma que le dio vida teórica a finales del siglo XIX, y ratificado por una historia de comportamiento endémico y estructural en las crisis de sobreproducción del actual modo de producción capitalista. Quiéralo o no, el aparato productivo que le dio vida al marketing como una fuerza social de cambio, y como una necesidad histórica del proceso de acumulación sostenida de capital, rápidamente se ha vuelto en su contra y los economistas integrales amarrados a los planteamientos más avanzados de las teorías de Marx y Keynes, están en deuda con la humanidad: Se necesita reconstruir un marketing que oriente realmente la producción al consumo y asegure el enfoque de las organizaciones de todo tipo al mercado, es decir, al consumidor (Garcés, 2010 y 2014).
Es posible, a manera de conclusión, realizar algunas observaciones finales a propósito de sus relaciones con las crisis actuales del modo de producción capitalista, insertadas en el contexto de la globalización, donde la frase socialismo o barbarie $^{32}$ revive con nuevo sentido. Cuestionar desde allí la visión reduccionista y lineal de la historia que hicieron algunos pensadores, es de suma importancia; así como el capitalismo tuvo muchas formas históricas de gestación e implantación, las sociedades poscapitalistas (puede dárseles cualquier nombre) que surgirán del seno mismo de sus contradicciones históricas tendrán embriones tan diversos como las diversas configuraciones nacionales de hoy así lo permitan. Es decir, así como la humanidad, tal como le marca el ritmo del proceso de acumulación sostenida de capital avanza en su proceso cíclico (en espiral creciente), insostenible a largo plazo $^{33}$, donde la miseria generalizada en medio de la abundancia relativa seguirá siendo la norma (la globalización actual), ella misma, como conjunto social, será la que decida el camino a seguir; y este tiene tantas historias futuras posibles, como formas de construcción social se vayan gestando en los diversos lugares del planeta Tierra.

Pero independientemente de ello, la sociedad que surja de las cenizas de la actual será tal cual el proceso histórico-social la marque; y lo que los datos

\footnotetext{
Se toma aquí en el sentido de Marx y Engels, y en línea con Rosa Luxemburgo y Samir Amín.

${ }^{33}$ Y el largo plazo es cada vez más corto, producto del avance de las nuevas fuerzas productivas, bajo sus formas y manifestaciones científico-tecnológicas.
} 
muestran (no solo los sociales) ${ }^{34}$, es que así como el capitalismo en la modernidad representó un avance profundo frente a las formas organizativas previas, ha dejado de ser ese motor revolucionario de transformación y avance de la humanidad, en medio de unas fuerzas productivas que ya casi no controla y que todo lo erosionan por donde se observa; esa contradicción histórico-social insalvable, que ha sido el motor mismo de la historia de la humanidad, es una de las pocas leyes sociales a las que puede hacerse referencia, y el marketing está jugando y jugará cada vez más allí, un papel relevante.

Es evidente que en las últimas intervenciones de Krugman y Stiglitz sobre lo que llaman la actual burbuja, aunque avance frente a las cavernas neoliberales y neoclásicas, son promulgadores y creyentes de las políticas salvíficas del modo de producción capitalista; como afirma Skidelsky (2009), estos neokeynesianos solo tienen una antigua disputa de familia con los neoneoclásicos; son como hermanos que comparten la misma madre (aunque esta sea de dudosa reputación), disputándose cada 5 años el escenario político; algunos incluso son tan atrevidos de asociarles con una izquierda (Partido Demócrata) y una ultra derecha (Partido Republicano) en los EEUU, algo que solo puede generar risas.

Skidelsky (2009) aterriza el tema al indicar que unos y otros tratan de ocultar sus exabruptos teóricos con excesos matemáticos, procurando mostrar pureza en el método, pero en ambos casos haciendo omisión de los reales aportes de Keynes y por supuesto, de Marx, a saber: que en el capitalismo la incertidumbre es una constante del proceso de inversión y las expectativas inciertas sobre el futuro hacen de este un sistema endeble, tambaleante, cíclico en espiral creciente, especulativo; es decir, uno que estructuralmente conlleva ciclos de auge-recesión, en los cuales las asignaciones y cálculos de probabilidades no siempre tienen sentido; no son simples burbujas, sino formas estructurales de autodestrucción endémica y enfermiza a largo plazo, como resultado de la misma actuación

\footnotetext{
34 Por la visión actual de los físicos cuánticos, acerca de la historia y evolución del universo, se sabe bajo la Teoría de Cuerdas que existen por lo menos 10 dimensiones diversas o universos paralelos (no 3, como alcanzamos a percibir con nuestros limitados sentidos); sin embargo, gracias al avance científico-tecnológico (las mismas fuerzas productivas a las que se refería Marx), igualmente se conocen dos cosas relevantes: 1) que el universo se expande a una tasa de crecimiento (velocidad) que ya ha superado el llamado umbral de colapso y por ello, las fuerzas de la gravedad no llevarán nunca a una especie de anti-big bang, sino que especies, planetas, estrellas y galaxias (además de miles de millones de cuerpos celestes que aún desconocemos), morirán frías y distantes unas de otras; y 2) que de las 10 dimensiones matemáticamente posibles, la vida tal como la concebimos (incluyendo la humana), sólo es posible en un universo de 3 dimensiones. Esto es lo que tiene perplejos a algunos científicos sociales: su estructural alejamiento del método científico y su renuncia a la observación de realidades, su entendimiento, su medición, y la capacidad predictiva asociada a todo ello. Eso ratifica más el por qué Carl Sagan pensaba a las puertas de su muerte que se estaba perdiendo la batalla contra la anticiencia (la charlatanería en sus múltiples formas); paradójicamente, Garcés (2005A) logra evidenciar en un estudio bibliométrico, que vía Google es más fácil encontrar personas escribiendo y proyectando sus ideas sobre temas de marketing-administración-management y economía neoclásica y neoliberal, cuyo volumen se mide en miles de millones de páginas, que gente escribiendo sobre temas abiertamente esotéricos (iluminación astral, tarot, aura, chacras, tercer ojo, etc.), que solo se pueden medir en centenares de millones.
} 
inercial de inversionistas que comparten la misma pasión incontrolable del usurero; no irracional, es la filosofía liberal misma, ensalzada a la categoría de ley.

Los neo-neoclásicos, negando simplemente el fenómeno a punta de creencias, ideología, supuestos, que logran mimetizar y encubrir bajo la categoría vulgar de leyes de la economía; y los neokeynesianos, creyendo que el problema se reduce simplemente a las asimetrías de información, que pueden ser resueltas con una buena gestión del Estado interventor. Unos y otros son incapaces de explicar tendencias a crisis estructurales de un modo de producción ya hoy anciano, mismas que surgen de una incertidumbre en los mercados, donde como dice Skidelsky (2009), un ciego guía a otro ciego: «Esta crisis es una crisis de ignorancia simétrica, no de información asimétrica».

En una línea diferente en la forma, pero cercana en el fondo, Akerlof y Shiller (2009) muestran unos Animal Spirits que se inscriben dentro de las corrientes de la economía conductual, asegurando que la conducta de los agentes económicos es totalmente irracional; algo que los marxistas de antaño (léase, bajo el pensamiento y obra de Marx), saben es una tremenda estupidez; es decir, cada régimen, según su modo de producción, conlleva una específica forma de pro- ducir y por tanto, de consumir; en este caso, el capitalismo es orientado por inversionistas privados, cuya pasión de acumulad, acumulad, enriqueceos es su leit motiv, mismo que les lleva a competir hasta la muerte ${ }^{35}$; algo que comparten con los usureros, pero lo que en estos últimos es una vulgar pasión irreprimible (irracional), en los primeros, es la forma misma que da movimiento a su proceso de acumulación ampliada y cíclica de capital (no siempre sostenida, más bien en espiral). Es su razón social de ser, su naturaleza de clase, no hay allí nada de irracional; no hay nada más racional que la filosofía liberal, su concepción de clase, y todo el andamiaje ideológico que han montado durante más de 200 años para hacer pensar a la humanidad que el fin de la historia ya llegó (Fukuyama, 1992 y 2012). En el panorama criollo (Colombia), solo que hay que observar al papel de la burguesía vende-patria, plutocrática y corrupta, que enquistada en el poder sólo busca sacar el provecho y lucro individual que sus relaciones comerciales con el norte le posibilite; no se trata de algo realmente humano, pero es ella la racionalidad liberal per se.

Así mismo, el análisis del consumo a espaldas del proceso mismo de producción, o su categorización de irracional por centrársele en el problema subjetivo/individual de clara tradición neoclásica y neoliberal, a espaldas de su visualización como categoría

\footnotetext{
35 Claro, haciendo siempre aquellos acuerdos momentáneos que les permita reacomodación industrial (grupos estratégicos o grupos competitivos); para verificar sus efectos en el campo específico del marketing, se sugiere revisar los trabajos de Garcés, 2007a, 2007b, 2007c y 2008.
} 
social (hombres permeados por una superestructura), que le impone una forma de vida propia de su modo de producción (cultura, ideología, marco regulatorio, etc.), es otra de las formas arquetípicas que la modernidad y la globalización asumen para camuflar el problema de fondo; es decir, se muestra como crítica en la forma, cuando de iure, en su fondo, acepta toda la visualización que el statu quo promulga para defender el ancien regimé, que hoy más que nunca saben está enfermo de muerte.

Jhon Gray, un filósofo de la modernidad (como él mismo se describe), plantea que «....aunque Marx tenía razón porque el mundo de la burguesía ha sido destruido, igualmente se equivocó, porque al mismo tiempo el comunismo ha sido derrotado» (Gray, 2011); y paradójicamente, en igual línea, con un título aparentemente contradictorio, Lord Meghnad Desai, miembro de la Cámara de los Lores y profesor emérito de la London School of Economics, indica que contrario a Marx, «El capitalismo está vivo y saludable, pero no en los países occidentales, ha emigrado a oriente» (Desai, 2011). Ambas posiciones están desarticuladas de la verdadera esencia del pensamiento de Marx, pero más importante, corresponden a interpretaciones periodísticas, mediáticas, ahistóricas, idealistas, que no resisten debate desde el materialismo histórico-dialéctico, por lo que resulta necesario hacer aquí las observaciones del caso.

Aunque el título de Gray es cierto, sus argumentos explicativos no podrían ser más desacertados. En primer lugar, porque Marx no construyó modelo alguno de la forma en que se gestionaría en la praxis algo llamado comunismo, y sus notas sueltas sobre el socialismo eran más bien descriptivas que normativas, razón por la cual las reelaboraciones políticas alrededor del tema y la visualización del modelo de desarrollo socialista como vía o camino alternativo al capitalismo salvaje, quedarían como tareas pendientes para las futuras generaciones; e incluso, el llamado socialismo real, no invalida su importancia y relevancia histórica, en este camino necesario y posible hacia la construcción del socialismo del siglo XXI; o es que todas la revoluciones burguesas no fueron involucionadas en su momento por las restauraciones enfeudizantes: a cada $\mathrm{Na}-$ poleón siempre le siguió su Luis XVIII.

Así, lo que estos filósofos de la modernidad no entienden y con ello le hacen juego a los politólogos defensores del ancien regimé, es que Marx fue un verdadero pensador integral, holístico, un científico que diseccionó en los mayores niveles de profundidad la manera como se gestó, se parió, se desarrolló y entró en su fase senil (aún en medio de una histórica juventud), este modo de producción condenado a su autodestrucción, como todos los que le han precedido. Sus conclusiones no podrían ser más desafortunadas: el mundo burgués no ha sido destruido, todo lo contrario, el ancien regimé goza aún de vida, atravesado hoy más que nunca por sus más destructivas metástasis; la burguesía, la 
verdadera burguesía cada vez más mundial y global (la plutocracia en el ejercicio del poder), ha logrado destrozar casi todas las relaciones antiguas y ha transformado todos los rincones y relaciones sociales del planeta; ha magnificado fuera de toda proporción la sentencia de Marx de que en el capitalismo todo se volvería mercancía (productos tangibles e intangibles), hasta la más profunda de las relaciones humanas.

Sus niveles de concentración económica hoy (poder, riqueza, activos, utilidades, etc.) han llegado a tal punto, que las 600 corporaciones mundiales y sus reales propietarios (los accionistas, no los gestores y administradores del capital, vulgares obreros de cuello blanco, como les llamaría Kalecki, 1977), concentran más del $70 \%$ de los activos estratégicos del planeta (Bonefield, 1998); y así, tal como lo muestra Amin (2009), un $20 \%$ de los habitantes del planeta (lógicamente ubicados en los llamados países ricos), consumen anualmente más del $80 \%$ de sus recursos estratégicos. Esto significa que el modelo neoclásico y neoliberal de la globalización solo logra profundizar aquellas condiciones económicas (producción y consumo), que tarde o temprano necesariamente le sacarán de madre.
El filósofo Gray tiene razón cuando afirma que Marx tenía razón, pero no bajo los argumentos que allí plantea, sino por el hecho relevante desde una visión científicohistórico-dialéctica, de que el pensamiento de Marx es vigente simple y llanamente por su método científico de tratamiento del fenómeno social; eso es lo que le hace un visionario y una mente excepcional, una ideología de clase, a pesar de que la dominante aún mantenga condiciones imperantes de superestructura que le permitirán por algún tiempo controlar el sistema; ¿cuánto más?, esa es la cuestión, porque como afirmaría Rosa Luxemburgo (1871-1919), retomando una célebre frase de Engels $^{36}$, la humanidad se enfrenta a una realidad histórica inalienable: socialismo o barbarie. $\mathrm{Y}$ claro, cuando se hace referencia a barbarie, se está hablando claramente de esa experiencia ratificada históricamente por la civilización globalizada del capitalismo; una que con dos guerras mundiales y múltiples guerritas localizadas al vaivén de las necesidades coyunturales del imperio norteamericano (de estructuralmente abiertas, como la doble invasión de Irak; a las más soterradas y genocidas prácticas de acorralamiento a naciones enteras que no se alinean con su propuesta globalizante, como el bloqueo a Cuba durante más de 50 años), demuestran con claridad que nunca ha habido más bar-

\footnotetext{
36 La frase socialismo o barbarie con que suele citarse a Rosa Luxemburgo corresponde realmente a una mención que hiciera en el Folleto Junius, donde dice textualmente: Federico Engels dijo una vez: "La sociedad capitalista se halla ante un dilema: avance al socialismo o regresión a la barbarie” (Luxemburgo, 1915, p. 275). Dice Luxemburgo, “... podemos ir hacia una sociedad des-alienada y una convivencia más racional y humana, el socialismo; o podemos continuar hundiéndonos en la barbarie, el capitalismo". Más adelante indica, "La libertad siempre ha sido y es la libertad para aquellos que piensen diferente".
} 
barie que durante esta etapa de avance del capitalismo moderno.

Finalmente, sobre la intervención de Lord Meghnad Desai, según la cual «el capitalismo está vivo y saludable, pero no en los países occidentales, ha emigrado a oriente», como diría un político corrupto colombiano ${ }^{37}$ : falso de toda falsedad. El socialismo no fue lo que murió hace 20 años; lo que feneció parcialmente fue un intento de modelo equivocado en su forma de gestión política y desarrollo social; es decir, uno que como concentración del poder y riqueza en manos de algunas castas burocráticas que no representaban los intereses de la sociedad rusa (en particular) y soviética (en general), terminó destruyéndose en medio de sus contradicciones y pugnas internas; y lo paradójico es que ese modelo y patrón de producción-acumulación ampliada demostró ser bastante eficiente (algunos lo identificaron como capitalismo monopolista de Estado) y de hecho, es una de las tendencias de concentración del capitalismo globalizante de nuestra era, y sus plutócratas al servicio del capital financiero mundial. Lo que pasa es que los soviéticos lo implementaron tan rápido, que amenazaron el poder del imperio regente de occidente y sus fuerzas en coalición.

EL SOCIALISMO (en mayúsculas) y sus múltiples y posibles formas de na- cimiento y devenir histórico, como forma organizativa social que premie los intereses de la colectividad y lo social, por encima del gusto (Bentham-Smith) y la bondad (Moore-Keynes) individual, están en la tarea constructiva de los verdaderos revolucionarios, científicos sociales y pensadores de izquierda. Y releyendo a Keynes, se puede observar sin problemas que sus planteamientos se corresponden con los de un moralista vergonzante del capitalismo, que añoraba una sociedad avanzada, superior, poscapitalista, claramente copiada de los diseños ideológicos de Marx sobre el comunismo científico; una donde la producción y el desarrollo científicotecnológico habrían llegado a tal nivel de avance, que los seres humanos no tendrían que trabajar para subsistir y sus necesidades estarían sobrecubiertas por el aparato productivo mundial: no habría entonces allí alicientes para producir con miras a un mercado en el que tales cosas se intercambiaran con el afán de lucro individual. Y así, una en cuya etapa de trasformación socialista, aún economía de mercado, requiere de conectores eficientes en los procesos de intercambio de valor entre oferentes y demandantes; es decir, de un marketing integral, humano y centrado en el consumidor, tal como el que se ha descrito en el presente trabajo, bajo el modelo dialéctico de marketing (MDM).

$37 \quad$ El exministro de Agricultura del Gobierno de Álvaro Uribe, condenado por la Procuraduría por un escándalo sobre los subsidios del programa Agro-Ingreso Seguro desviados y entregados a terratenientes y gamonales ricos de algunas regiones del país, y a quien la prensa le ha dado el sobrenombre de Uribito: hoy día, prófugo de la justicia y emigrado a EEUU por recomendación de su líder político. 
Pero bajo su argumentación, era el capitalismo el que llevaría directamente a ello, dado que los capitalistas casi de manera mágica se volverían buenos (un argumento moral y ético) y se irían transformando paulatinamente en esos seres filantrópicos y altruistas con los que Keynes soñaba; más ideología religiosa, en línea con la tradición bíblica. Nunca, clase alguna, en el devenir histórico de la lucha de clases (motor de la historia) ha renunciado a sus intereses de clase-grupo; ¿por qué este modo de producción pariría una clase social tan exótica que esgrimirá en algún momento tales características? Esa es la diferencia interpretativa real existente entre Mark (método histórico-dialéctico) y Keynes (método lineal de relaciones causaefecto); sin dejar de mencionar que este último además de plagiar muchas de las ideas de Marx (sin dar reconocimiento alguna de las mismas, salvo en algunas acotaciones de correspondencia privada que acaban de reaparecer en Cambridge), lucró en carne propia las mieles del proceso de inversión, de la vulgar especulación financiera y en la bolsas, donde logró acumular una interesante fortuna (¡qué paradoja!).

De allí la más relevante conclusión de este escrito: en la actual coyuntura y fase del modo de producción capitalista y su proceso globalizante de acumulación sostenida de capital, desarrollar un marketing teórico robusto e integral, es una tarea indetenible; pero al mismo tiempo, pensar desde la izquierda no es una opción, es una obligación para los verdaderos científicos sociales y demócratas del mundo, que se enfrentan a la única condición posible en el futuro: socialismo o barbarie.

\section{REFERENCIAS}

Akerlof, G. A. \& Shiller, R. J. (2009). Animal spirits: How human psychology drives the economy, and why it matters for global capitalism. New Jersey: Princeton University Press.

American Marketing Association -AMA- (2004. 2007). AMA Definition of marketing. Retrieved from http://www.marketingpower.com/Community/ARC/Pages/ Additional/Definition/default.aspx

Amin, S. (2009). La crisis. Salir de la crisis del capitalismo o salir del capitalismo en crisis. España: El Topo.

Anderson, P. (1982). Marketing strategic planning and the theory of the firm. $J$. of Marketing, 46, 15-26. 
Anderson, P. (1983). Marketing, scientific progress, and scientific method. Journal of Marketing, 47, 18-31.

Anderson, P. (1992). Zones of engagement. London: Verso.

Ansoff, H. I. (1968). Corporate strategy. New York: Mc Graw-Hill.

Bartels, R. (1988). The history of marketing thought. Columbus: Publishing Horizons Inc.

Bartels, R. \& Jenkins, R. L. (1977). Macromarketing. Journal of Marketing, 41, 1720.

Bonefeld, W. (1998, julio). Las políticas de la globalización: ideología y crítica. Revista Globalización.

Bunge, M. (1980). Ética y ciencia. Buenos Aires: Siglo Veinte.

Bunge, M. (1985). Pseudociencia e ideología. Madrid: Alianza Universidad.

Buskirk, R. H. (1961). Principles of marketing. Nueva York: Holt, Rinehart y Winston.

Carlzon, J. (1987). Putting the customer first: the key to service strategy. En Lovelock, (1991). Services marketing: text, cases and readings (pp. 424-432). UK: Prentice Hall International Editions.

Cundiff, E. W. \& Still, R. R. (1964). Basic marketing: concepts, environment and decision. Nueva Jersey: Prentice Hall, Englewood Cliffs.

Davidson, P. (2003). ¿Qué es erróneo en el consenso de Washington y qué debemos hacer? Cuadernos de Economía, 22(39).

Day, G. S. (1990). Market driven strategy: processes for creating value. New York: The Free Press.

Day, G. S. (1992). Marketing's contribution to the strategy dialogue. Journal of the Academy of Marketing Science, 20(4), 323-329.

Day, G. S. (1994A). The capabilities of market-driven organizations. Journal of Marketing, 58(4), 37-52. 
Day, G. S. (1994B, Summer). Continuous learning about markets. California Management Review, 9-31.

Day, G. S. (1995). Advantageous Alliances. Journal of the Academy of Marketing Science, 23(4), 297-300.

Day, G. S. (1996). Market driven organizations: building marketing capabilities. Pennsylvania: The Wharton School, University of Pennsylvania.

Day, G. S. (2000). La organización que actúa en función del mercado. Bogotá: Norma.

Day, G. S. \& Van den Bulte, C. (2002). Superiority in customer relationship management: consequences for competitive advantage and performance. Marketing Science Institute, Report Summary (2-123), 1-41.

Day, G. S. \& Wensley, R. (1983). Marketing theory with strategic orientation, J. of Marketing, 47, 79-89.

Day, G. S. \& Wensley, R. (1988). Assessing advantage: a framework for diagnosing competitive superiority. Journal of Marketing, 52, 1-20.

Day, G. S. \& Wind, J. (1980). Strategic planning and marketing: time for a constructive partnership. Journal of Marketing, 44, 7-8.

Desai, M. J. (2011, 28 de sept.). El capitalismo está vivo y saludable, (pero no en Occidente). $B B C$ de Londres. Recuperado de http://www.bbc.co.uk/mundo/noticias/2011/09/110928_capitalismo_vivo_aa.shtml

Drucker, P. F. (1954). The practice of management. New York: Harper Business.

Economía Planeta (1980). Diccionario Enciclopédico. Barcelona: Planeta.

Feldman, L. P. (1971). Societal adaptation: a new challenge for marketing. $J$. of Marketing, 35, 54-60.

Fukuyama, F. (1992). El fin de la historia y el último hombre. Barcelona: Planeta.

Fukuyama, F. (2012, Jan/Feb). The future of history. ¿Can liberal democracy survive the decline of the middle class? Foreign Affairs, Council on Foreign Relations 
Inc. Retrieved from http://www.viet-studies.info/kinhte/FA_FutureOfHistory_ Fukuyama.htm

Fullerton, R. A. (1988). How modern is modern marketing? Marketing's evolution and the myth of the «Production Era». Journal of Marketing, 52(1), 108-125.

Garcés C., J. E. (1994). Metodología para el desarrollo de plan estratégico de marketing -PEM. Material de clase de los cursos Marketing Estratégico y Marketing Operativo, Postgrado de Psicología del Consumidor. Bogotá: Universidad Konrad Lorenz.

Garcés, J. E. (2003, 14 de oct.). El marketing: un paradigma balbuceando, en un capitalismo mutando. En Conferencia en Expo academia. Universidad Konrad Lorenz, Bogotá, Colombia.

Garcés, J. E. (2005, enero-junio). El marketing: un paradigma balbuceando, en un capitalismo mutando. Revista Poliantea 3, 53-87.

Garcés, J. E. (2006, febrero). Revista Suma Administrativa, 1(1), 32-71.

Garcés, J. E. (2005, 22 de sep.). ¿Es posible la ciencia del marketing? En Conferencia en Expo academia, Universidad Konrad Lorenz, Bogotá, Colombia.

Garcés, J. E. (2007, 10-12 de oct. 2009 y 2012). Marketing y responsabilidad social empresarial RSE. En Ponencia, 1er. Congreso Iberoamericano de RSE, Cali, Colombia, Universidad Santiago de Cali.

Garcés, J. E. (2007 , oct.). Grupos estratégicos en la banca colombiana 1995-2004. Revista Vox Populi, 6, 3-66.

Garcés, J. E. (2007B). Revisión del concepto de grupo estratégico y propuesta de definición para aplicaciones en el ámbito colombiano, Revista Innovar, 17(30), 99-111. Recuperado de http://redalyc.uaemex.mx/pdf/818/81803008.pdf

Garcés, J. E. (2007C): Grupos cognitivos (estratégicos y competitivos) en AFP de Colombia al 2005. Revista Suma Psicológica, 14(1), 107-200. Recuperado de http://openjournal.fukl.edu/index.php/sumapsi/article/view/40/0

Garcés, J. E. (2008): Grupos estratégicos en la banca colombiana: análisis estático y dinámico. Revista Innovar, 18(32), 195-226. Recuperado de http://www.scielo. 
org.co/pdf/inno/v18n32/v18n32a11.pdf

Garcés, J. E. (2009, oct.). Marketing y responsabilidad social empresarial RSE. Revista Vox Populi, 8, 29-44.

Garcés, J. E. (2010). Desarrollo de un modelo de medición de la orientación al mercado con real foco en el consumidor, y pilotaje en el sector asegurador colombiano. Tesis para la obtención del título de Magíster en Psicología del Consumidor, Posgrado en Psicología del Consumidor de la Universidad Konrad Lorenz, Bogotá, Colombia.

Garcés, J. E. (2012). Investigaciones en psicología del consumidor. Barranquilla, Colombia: INPSICON. Recuperado de www.inpsicon.com/elconsumidor/ archivos/Maryres.pdf).

Garcés, J. E. (2014). Dialectical model of marketing versus trends and fashions. Journal of Business and Management Sciences, 2(3), 58-68. Retrieved from http://pubs.sciepub.com/jbms/2/3/1.

Garcés, J. E. (2014). Dialectical model of marketing versus trends and fashions. Global Journal of Management and Business Research: E, Marketing, 14(5), 23-35. Retrieved from https://globaljournals.org/GJMBR_Volume14/EJournal_GJMBR_(E)_Vol_14_Issue_5.pdf

Gray, J. (2011, 11 de sep.). Karl Marx tenía razón. BBC de Londres. Recuperado de http://www.bbc.co.uk/mundo/noticias/2011/09/110906_marx_capitalismo. shtml.

Grönroos, C. (1983). Innovative marketing strategies and organization structures for services firms. In Lovelock (1991). Services marketing: text, cases and readings, (pp. 433-448). UK: Prentice Hall Int.

Grönroos, C. (1989). Defining marketing: a market-oriented approach. European J. of Mark., 23(1), 54-58.

Grönroos, C. (1990). Service management and marketing. Managing the moments of truth in service competition. Massachusetts-USA: Lexington Books.

Grönroos, C. (1994). Marketing y gestión de servicios. Madrid: Díaz de Santos. 
Grönroos, C. (1995). Relationship marketing: the strategy continuum. Journal of the Academy of Marketing Science, 23(4), 252-254.

Gummesson, E. (1987). Marketing: a long-term interactive relationship. Research Report. Sweden: Marketing Technology Centre (MTC), Stockholm University.

Gummesson, E. (1988). Marketing: a long-term interactive relationship. Gothenburg, Sweden: Anderson Sandberg Dhein.

Gummesson, E. (1991). Marketing orientation revisited. The crucial role of the parttime marketer. European Journal of Marketing, 25(2), 60-75.

Hawking, S. W. (1988). Historia del tiempo. Madrid: Crítica.

Hirsch, J. (1995). Der «Nationale» Wettbewersstaat: Demokratie, und Politic im globalen Kapitalismus. Berlin: Edition Id-Archive.

Hirsch, J. (1996). Globalización, capital y Estado. México: Universidad Autónoma Metropolitana.

Hunt, S. D. (1982). The macromarketing/micromarketing dichotomy: a taxonomical model. Journal of Marketing, 46, 11-26.

Hunt, S. D. (1991). Modern marketing theory: critical issues in the philosophy of marketing science. Cincinnati: South-Western Publishing.

Kalecki, M. (1977). Ensayos escogidos/dinámica de la economía capitalista, 19331970. México: F.C.E.

Katona, G. (1963). Análisis psicológico del comportamiento económico. Madrid: Rialp.

Kelley, E. J. (1971). Marketing changing social environmental role. Journal of Marketing, 35, 1-2.

Keynes, J. M. (1936). La teoría general de la ocupación, el interés y el dinero. México: F.C.E.

Kotler, P. (1967). Marketing management. (2nd ed). Englewood Cliffs-New Jersey: Prentice Hall. 
Kotler, P. \& Zaltman, G. (1971). Social marketing: an approach to planned social change. Journal of Marketing, 35, 3-12.

Kuhn, T. (1971). La estructura de las revoluciones científicas. México: Fondo de Cultura Económica.

Lavidge, R. J. (1970). The growing responsibilities of marketing. Journal of Marketing, 34(1), 25-28.

Lenin, V. I. (1917). El imperialismo, fase superior del capitalismo (esbozo popular). Petrogrado: Parus.

Lenin, V. I. (1985). El imperialismo, fase superior del capitalismo (esbozo popular). Bogotá: Fondo Editorial Suramérica.

Luxemburgo, R. (1915). Folleto de Junius: la crisis de la socialdemocracia alemana. En Obras escogidas. Recuperado de http://www.marxists.org/espanol/ luxem/09E1\%20folletoJuniusLacris

acrisisdelasocialdemocraciaalemana_0.pdf.

Martínez, M. (2000). Ciencia y marketing. Manual para investigadores y doctorando en Ciencia Social. Madrid: ESIC.

Marx, K. (2000). El Capital. Crítica de la economía política clásica. México: F. C. E.

McCarthy, E. J. (1960). Basic marketing: a managerial approach. Homewood, Illinois: R. D. Irwin.

Moyer, R. (1972). Macromarketing: a social perspective. New York: John Wiley \& Son.

Phillips, C. F. \& Duncan, D. J. (1968). Marketing, principles and methods. Homewood, Illinois: Richard D. Irwin.

Popper, K. (1957). The poverty of historicism. London: Routledge and Paul.

Popper, K. (1967). El desarrollo del conocimiento científico. Conjeturas y refutaciones. Buenos Aires: Paidós. 
Porter, M. E. (1979). The structure within industries and companies performance. Review of Economics and Statistics, 61, 214-227.

Porter, M. E. (1982). Estrategia competitiva. Técnicas para el análisis de los sectores industriales y de la competencia. Madrid: CECSA.

Porter, M. E. (1990). Ventaja competitiva: crear y mantener un desempeño superior. Madrid: CECSA.

Quintanilla, I. (2002). Psicología del consumidor. Madrid: Prentice Hall.

Ries A. \& Ries, L. (2000). El nuevo posicionamiento. Bogotá: McGraw-Hill.

Ries, A. \& Trout, J. (1990). Posicionamiento: el concepto que ha revolucionado la comunicación publicitaria y la mercadotecnia. México: McGraw-Hill.

Robinson, J. (1959). Ensayos de economía poskeynesiana. México: Fondo de Cultura Económica.

Robinson, J. (1973). Economía de la competencia imperfecta. Barcelona: Martínez Roca.

Sallenave, J.P. (1995). La teoría L: manual de antigerencia. Bogotá: Tercer Mundo.

Sarabia, F. (Coord.). (1999). Metodología para la investigación en marketing y dirección de empresas. Madrid: Pirámide.

Say, J.B. (1803). Traité d'économie politique, ou simple exposition de la manière dont se forment, se distribuent ou se consomment les richesses. Paris: Pub. Horace Say.

Say, J.B. (1972). Traité d'économie politique, ou simple exposition de la manière dont se forment, se distribuent ou se consomment les richesses. Paris: CalmannLévy Éditeur, Collection Perspectives de l'économique-Les fondateurs. 572 p. Recuperado de http://classiques.uqac.ca/classiques/say_jean_baptiste/traite_ eco_pol/traite_eco_pol.html

Skidelsky, R. (2009). El regreso de Keynes. Barcelona: Crítica. 
Spencer, H. \& Moinpour, R. (1972). Fear appeals in marketing. A social perspective, J. of Market., 36, 39-43.

Stanton, W. J. (1964). Fundamentals of Marketing. USA: McGraw-Hill.

Stiglitz, J. E. (1996). Whither Socialism? Massachusetts: MIT Press.

Stiglitz, J. E. (2002). El malestar en la globalización. Madrid: Taurus.

Stiglitz, J. E. (2003). Los felices 90: la semilla de la destrucción. Bogotá: Taurus.

Stiglitz, J. E. (2006). Cómo hacer que funcione la globalización. Madrid: Taurus.

Stiglitz, J. E. (2010). Caída libre. El libre mercado y el hundimiento de la economía mundial. Madrid: Taurus.

Wallerstein, I. (2007). La crisis estructural del capitalismo. Bogotá: Ediciones Desde Abajo.

Webster, F. E. (Jr.) (1981). Top management's concerns about marketing issues for the 1980's. Journal of Marketing, 45, 9-16.

Webster, F. E. (Jr.) (1988). The rediscovery of the marketing concept. Business Horizons, 31, 9-16.

Webster, F. E. (Jr.) (1992). The changing role of marketing in the corporation. J. of Marketing, 56, 1-17.

Webster, F. E. (Jr.) (1994). Market-driven management: using the new marketing concept to create a customer-oriented company. New York: John Wiley \& Sons.

Weintraub, E. R. (1985). Microfundamentos: la compatiblidad entre la micro y la macroeconomía. Madrid: Alianza. 